\title{
Urinary Proteome and Systolic Blood Pressure as Predictors of 5-Year Cardiovascular and Cardiac Outcomes in a General Population
}

\author{
Zhen-Yu Zhang, Lutgarde Thijs, Thibault Petit, Yu-Mei Gu, Lotte Jacobs, Wen-Yi Yang, \\ Yan-Ping Liu, Thomas Koeck, Petra Zürbig, Yu Jin, Peter Verhamme, Jens-Uwe Voigt, \\ Tatiana Kuznetsova, Harald Mischak, Jan A. Staessen
}

\begin{abstract}
In a previous cross-sectional study, we identified a multidimensional urinary classifier (HF1), which was associated with left ventricular dysfunction. We investigated whether HF1 predicts cardiovascular end points over and beyond traditional risk factors. In 791 randomly recruited Flemish (mean age, 51.2 years; 50.6\% women), we quantified HF1 by capillary electrophoresis coupled with mass spectrometry. In addition, we measured cardiovascular risk factors. HF1 averaged -0.97 $\mathrm{U}$ (range, -3.26 to 2.60). Over 6.1 years (median), 35 participants died and 63, 45, and 22 experienced fatal or nonfatal cardiovascular, cardiac, or coronary events, respectively. The incidence of fatal combined with nonfatal cardiovascular and cardiac end points, standardized for sex and age, increased across thirds of the HF1 distribution $(P \leq 0.014)$, whereas trends for all-cause mortality and coronary events were nonsignificant $(P \geq 0.10)$. The multivariable-adjusted hazard ratios $(+1-\mathrm{SD})$ were 1.30 (95\% confidence interval, $1.03-1.65 ; P=0.029)$ and $1.39(1.06-1.84 ; P=0.018)$ for cardiovascular and cardiac events in relation to HF1. For systolic pressure, the corresponding estimates were $0.97(0.74-1.28 ; P=0.85)$ and $0.93(0.67-1.29 ; P=0.66)$, respectively. The HF1 upper thresholds optimized by maximizing Younden's index were -0.50 and $-0.36 \mathrm{U}$ for cardiovascular and cardiac end points, respectively. Prognostic accuracy significantly $(P \leq 0.006)$ improved by adding HF1 to Cox models already including the other baseline predictors. Sensitivity analyses, from which we excluded 71 participants with previous cardiovascular disease, were confirmatory. In conclusion, over a 6-year period, the urinary proteome, but not systolic pressure, predicted cardiovascular and cardiac disease. (Hypertension. 2015;66:52-60. DOI: 10.1161/HYPERTENSIONAHA.115.05296.) • Online Data Supplement
\end{abstract}

Key Words: biomarker cardiovascular disease $\mathbf{m o r b i d i t y}$ mortality $\boldsymbol{\square}$ proteomics

$\mathrm{R}^{\mathrm{c}}$ ecent publications, reviewed elsewhere, ${ }^{1}$ proved the feasibility of developing multidimensional classifiers based on the urinary proteome that are associated with chronic kidney disease, ${ }^{2}$ urothelial cell carcinoma, ${ }^{3}$ prostate cancer, ${ }^{4}$ or coronary heart disease. ${ }^{5}$ However, these urinary proteomic markers were mainly established in selected patients matched with controls or in cohorts of diseased patients. In 2012, we identified in a preliminary case-control study 85 urinary peptides, mainly up- or downregulated collagen fragments, that discriminated 19 hypertensive patients with asymptomatic diastolic left ventricular dysfunction from 19 controls. ${ }^{6}$ With adjustments applied for multiple testing, 3 urinary peptide biomarkers remained significant. ${ }^{6}$ In a subsequent cross-sectional study, we demonstrated that left ventricular diastolic dysfunction was associated with this proteomic signature in a random population sample. ${ }^{7}$ A study in the same population revealed that the urinary proteome predicted progression of chronic kidney disease from grade 2 or lower to stage 3 or higher. ${ }^{8}$ In the light of our previous observations, ${ }^{6-8}$ we investigated in a random population sample whether the urinary proteome predicts cardiovascular events over and beyond traditional risk factors.

\section{Methods}

\section{Study Participants}

The Ethics Committee of the University of Leuven approved the Flemish Study on Environment, Genes and Health Outcomes..,10

\footnotetext{
Received February 27, 2015; first decision March 15, 2015; revision accepted April 17, 2015.

From the Studies Coordinating Centre, Research Unit Hypertension and Cardiovascular Epidemiology (Z.-Y.Z., L.T., T.P., Y.-M.G., L.J., W.-Y.Y., Y.P.L., Y.J., T. Kuznetsova, J.A.S.), Centre for Molecular and Vascular Biology (P.V.), and Research Unit Cardiology (J.-U.V.), KU Leuven Department of Cardiovascular Sciences, University of Leuven, Leuven, Belgium; Mosaiques Diagnostic and Therapeutics GmbH, Hannover, Germany (T. Koeck, P.Z., H.M.); BHF Glasgow Cardiovascular Research Centre, University of Glasgow, United Kingdom (H.M.); and R\&D VitaK Group, Maastricht University, Maastricht, The Netherlands (J.A.S.).

This article was sent to Robert M. Carey, Consulting Editor, for review by expert referees, editorial decision, and final disposition.

The online-only Data Supplement is available with this article at http://hyper.ahajournals.org/lookup/suppl/doi:10.1161/HYPERTENSIONAHA. 115.05296/-/DC1.

Correspondence to Jan A. Staessen, Studies Coordinating Centre, Research Unit Hypertension and Cardiovascular Epidemiology, KU Leuven Department of Cardiovascular Sciences, University of Leuven, Campus Sint Rafaël, Kapucijnenvoer 35, Box 7001, BE-3000 Leuven, Belgium. E-mail jan.staessen@ med.kuleuven.be or ja.staessen@ maastrichtuniversity.nl

(C) 2015 American Heart Association, Inc.
} 
Recruitment started in 1985 and continued until 2004. The initial participation rate was $78.0 \%$. The participants were repeatedly followed up. ${ }^{9,10}$ From May 2005 until May 2010, we mailed an invitation letter to 1208 former participants for a follow-up examination. However, 153 were unavailable because they had died earlier $(n=26)$, because they had been institutionalized or were too ill $(n=27)$, or because they had moved out of the area $(n=100)$. Of the remaining 1055 former participants, 828 renewed informed consent. The participation rate was therefore $78.5 \%$. We excluded 37 participants from analysis because urine samples for urinary proteomics were unavailable $(n=22)$ or because they were lost to follow-up $(n=15)$. Thus, the outcome cohort included 791 participants (for details, see Figure S1 in the online-only Data Supplement).

\section{Assessment of Outcome}

At annual intervals, we ascertained vital status through 6 October 2014 via the Belgian Population Registry in Brussels, Belgium. We obtained the International Classification of Disease codes for the immediate and underlying causes of death from the Flemish Registry of Death Certificates. For all 791 participants, we collected information on the incidence of nonfatal events either via a follow-up visit at the examination center with repeat administration of the same standardized questionnaire as used at baseline $(n=637)$ or via a structured telephone interview $(\mathrm{n}=119)$.

Coronary events included sudden death, myocardial infarction, acute coronary syndrome, new-onset angina pectoris, ischemic cardiomyopathy, and coronary revascularization. Cardiac events additionally included heart failure, pulmonary heart disease, new-onset atrial fibrillation, life-threatening arrhythmias, and high-degree atrioventricular block requiring pacemaker implantation. Cardiovascular events comprised cardiac end points, stroke, transient ischemic attack, aortic aneurysm, arterial embolism, and revascularization of peripheral arteries. To assess the symptoms associated with heart failure, we administered the London School of Hygiene questionnaires on cardiovascular and respiratory symptoms and dyspnea. Physicians ascertained the diseases reported on the death certificates or by the questionnaires and interviews against the medical records of general practitioners or hospitals. For all end points within a category, we censored participants from analysis after the occurrence of the first event.

\section{Urinary Proteomics}

To assess the urinary proteome-based HF1 classifier, 24-h urine samples were processed and analyzed using capillary electrophoresis coupled with mass spectrometry as described previously. ${ }^{11}$ The online-only Data Supplement (pages 2-3) gives detailed information on the preparation and processing of the urine samples. The data (on abundance) of the predefined urinary peptide biomarkers were combined into a single summary variable, using the support-vector machine-based MosaCluster software, version 1.7.0. In the present study, we used the previously published multidimensional classifier HF1, which is associated with decreased left ventricular function and which combines information from 85 peptide fragments identified in 19 patients with diastolic LV dysfunction and 19 controls. ${ }^{6}$ How support-vector machine modeling establishes the HF1 classifier is described in the onlineonly Data Supplement (pages 3-4). In addition, the online-only Data Supplement provides information on the peptides making up HF1 (Table S1) and sequenced peptides with known amino-acid sequence (Table $\mathrm{S} 2$ ).

\section{Other Measurements}

Blood pressure was the average of 5 consecutive auscultatory readings obtained according to European guidelines with a standard mercury sphygmomanometer with the participant in the seated position for at least 10 minutes. As described elsewhere, we applied a stringent quality control program to the blood pressure measurements, looking for digit and number preference. ${ }^{12,13}$ Hypertension was a blood pressure of at least $140 \mathrm{~mm} \mathrm{Hg}$ systolic or $90 \mathrm{~mm} \mathrm{Hg}$ diastolic or use of antihypertensive drugs. Body mass index was weight in kilograms divided by height in meters squared. Venous blood samples were drawn for measurement of plasma glucose and serum total and highdensity lipoprotein cholesterol, creatinine, and $\gamma$-glutamyltransferase (index of alcohol intake). Glomerular filtration rate was derived by the Chronic Kidney Disease Epidemiology Collaboration equation. ${ }^{14}$ Diabetes mellitus was a self-reported diagnosis, a condition mentioned on the death certificate or in records held by general practitioners or hospitals, antidiabetic drug intake, a fasting plasma glucose level of at least $126 \mathrm{mg} / \mathrm{dL}$, or a random blood glucose of at least $200 \mathrm{mg} / \mathrm{dL} .^{15}$

\section{Statistical Analysis}

For database management and statistical analysis, we used the SAS system, version 9.3 (SAS Institute Inc., Cary, NC). Means were compared using the large-sample z-test or ANOVA and proportions by Fisher exact test. Statistical significance was a 2-sided significance level of 0.05 .

In exploratory analyses, we plotted incidence rates by tertiles of the urinary biomarker, while standardizing for sex and age group ( $<40$ years; $40-60$ years; $>60$ years) by the direct method. In categorical analyses with adjustments applied for sex and age, we plotted the cumulative incidence of cardiovascular and cardiac endpoints by thirds of the HF1 distribution. We used Cox regression to compute standardized hazard ratios, which for continuous variables express the risk associated with a 1-standard deviation (SD) increment in the urinary biomarker. All models accounted for clustering of failure times within pedigrees by fitting a shared frailty model. We checked the proportional hazard assumption using the Kolmogorov-type supremum test. The baseline characteristics considered as covariables in Cox regression were sex, age, body mass index, systolic blood pressure, fasting plasma glucose, serum creatinine, the total-to-high-density lipoprotein cholesterol ratio, $\gamma$-glutamyltransferase (as index of alcohol intake), smoking, history of cardiovascular disease, and treatment with diuretics (thiazides, loop diuretics, and aldosterone antagonists), $\beta$-blockers, inhibitors of the renin-angiotensin system (angiotensin-converting enzyme inhibitors or angiotensin type-1 receptor blockers), vasodilators (calcium channel blockers or $\alpha$-blockers), or other antihypertensive drugs. We identified covariables to be retained in the analyses by a step-down procedure, removing the least significant covariable at each step until all $P$ values of covariables were $<0.15$. We applied the generalized $R^{2}$ statistic to assess the contribution of HF1 and systolic blood pressure to risk over and beyond other risk factors. We calculated the multivariable-adjusted 5-year absolute risk of a cardiovascular or cardiac event across thirds of the distributions of HF1 and systolic blood pressure.

Finally, we determined optimal discrimination limits for HF1 by maximizing Younden's index (the maximum of sensitivity plus specificity minus 1 ). We then assessed the added prognostic accuracy of the optimized thresholds, using the integrated discrimination improvement (IDI) and the continuous net reclassification improvement (NRI) ${ }^{16}$ IDI is the difference between the discrimination slopes of the basic model and the basic model extended with HF1. The discrimination slope is the difference in predicted probabilities (\%) between subjects with and without end point. To calculate NRI, ${ }^{16}$ we predicted in each subject the 5-year risk for an event from a Cox model with and without HF1. If $P_{\text {(up/event) }}$ is the percentage of subjects with events whose predicted probability is increased by adding HF1 to the model and if $P_{\text {(up/nonevent) }}$ is the percentage of subjects without events whose predicted probability is increased, then NRI equals $2 \times\left[P_{\text {(up/event) }}-P_{\text {(up/ }}\right.$ nonevent)].

\section{Results}

\section{Characteristics of Participants}

Of 791 participants, $400(50.6 \%)$ were women. All subjects were White Europeans. Mean values (SD) in all participants combined were 51.2 (15.7) years (interquartile range [IQR], 41.3-61.8 years) for age, 129.6 (17.7) and 79.7 (9.6) $\mathrm{mm} \mathrm{Hg}$ 
for systolic and diastolic blood pressure, 26.5 (4.3) $\mathrm{kg} / \mathrm{m}^{2}$ for body mass index, and $5.26(0.97) \mathrm{mmol} / \mathrm{L}$ for total cholesterol. Of 3955 systolic and 3955 diastolic blood pressure readings, only $10(0.13 \%)$ ended on an uneven number. With regards to number preferences, the 5 consecutive blood pressure readings included 3 identical systolic or diastolic values in 340 instances (4.3\%) and 5 identical values in only a single participant.

Of all participants, $340(43.0 \%)$ had hypertension, of whom $209(61.5 \%)$ were on antihypertensive drug treatment, $27(3.4 \%)$ had a history of diabetes mellitus, and 27 $(3.4 \%)$ reported previous cardiovascular disease. The antihypertensive drug classes used were diuretics in $84(10.6 \%)$ participants, $\beta$-blockers in $124(15.7 \%)$, inhibitors of the renin-angiotensin system in $68(8.6 \%)$, and vasodilators in 39 (4.9\%). Among 209 treated patients, 122 (58.4\%) were on monotherapy; 69 (33.0\%) were taking 2 drug classes; and $18(8.6 \%)$ were taking $\geq 3$. Of 400 women and 391 men, $80(20.0 \%)$ women and $80(20.5 \%)$ men were smokers and $225(56.3 \%)$ women and $323(82.6 \%)$ men reported intake of alcohol. In smokers, median tobacco use was 13 cigarettes per day (IQR, 7-20 cigarettes per day). In drinkers, the median alcohol consumption was $8 \mathrm{~g}$ per day (IQR, 3-14 g per day).

Table 1 lists the characteristics of participants by thirds of the HF1 distribution (median; -1.03 ; IQR, -1.60 to -0.44 ). Age, body mass index, central obesity, blood pressure, serum creatinine, blood glucose and $\gamma$-glutamyltransferase, and the total-to- high-density lipoprotein cholesterol ratio all $(P \leq 0.002)$ increased with higher HF1 category, whereas estimated glomerular filtration rate decreased $(P<0.0001)$. The prevalence of hypertension, being treated for hypertension, having a history

Table 1. Baseline Characteristics of 791 Participants by Thirds of the HF1 Distribution

\begin{tabular}{|c|c|c|c|c|}
\hline Characteristic & $<-1.42$ & -1.42 to -0.68 & $\geq-0.68$ & $P$ Value \\
\hline Number in category & 264 & 263 & 264 & \\
\hline \multicolumn{5}{|l|}{ Number of subjects, \% } \\
\hline Women & $138(52.3)$ & $133(50.6)$ & $129(48.9)$ & 0.74 \\
\hline Smokers & 57 (21.6) & $60(22.8)$ & $43(16.3)$ & 0.14 \\
\hline Drinking alcohol & $185(70.1)$ & $191(72.6)$ & $172(65.2)$ & 0.17 \\
\hline Hypertension & $80(30.3)$ & $94(35.7)$ & $166(62.9) \S$ & $<0.0001$ \\
\hline Antihypertensive treatment & $37(14.0)$ & $50(19.0)$ & $122(46.2) \S$ & $<0.0001$ \\
\hline History of CVD & $7(2.7)$ & $4(1.5)$ & $16(6.1) \dagger$ & 0.011 \\
\hline History of diabetes mellitus & $3(1.1)$ & $7(2.7)$ & $17(6.4)^{\star}$ & 0.003 \\
\hline \multicolumn{5}{|l|}{ Mean (SD) of characteristic } \\
\hline Age, y & $45.6(15.3)$ & $50.4(14.3) \ddagger$ & $57.5(15.0) \S$ & $<0.0001$ \\
\hline Body mass index, $\mathrm{kg} / \mathrm{m}^{2}$ & $25.6(3.8)$ & $26.0(4.0)$ & $28.0(4.8) \S$ & $<0.0001$ \\
\hline Waist-to-hip ratio & $0.85(0.08)$ & $0.87(0.08)^{\star}$ & $0.90(0.08) \S$ & $<0.0001$ \\
\hline \multicolumn{5}{|l|}{ Office blood pressure, mm Hg } \\
\hline Systolic pressure & $126.6(17.3)$ & $127.9(16.7)$ & $134.3(18.2) \S$ & $<0.0001$ \\
\hline Diastolic pressure & $78.4(9.6)$ & 79.7 (9.5) & $81.1(9.6)$ & 0.004 \\
\hline Mean arterial pressure & $94.4(10.7)$ & $95.8(10.5)$ & $98.9(10.7) \ddagger$ & $<0.0001$ \\
\hline Heart rate, bpm & $62.6(8.6)$ & $63.4(9.3)$ & $64.4(11.1)$ & 0.10 \\
\hline \multicolumn{5}{|l|}{ Biochemical data } \\
\hline Serum creatinine, $\mu \mathrm{mol} / \mathrm{L}$ & $81.8(13.3)$ & $83.7(13.1)$ & $86.7(19.8)^{\star}$ & 0.002 \\
\hline eGFR, mL/min/1.73 m² & $83.9(16.4)$ & $80.2(16.2) \dagger$ & 76.3 (16.2)† & $<0.0001$ \\
\hline Total cholesterol, mmol/L & $5.13(0.95)$ & $5.32(0.98)^{\star}$ & $5.33(0.98)$ & 0.028 \\
\hline HDL cholesterol, mmol/L & $1.45(0.34)$ & $1.45(0.37)$ & $1.37(0.32) \dagger$ & 0.008 \\
\hline THR & $3.70(0.98)$ & $3.84(1.03)$ & $4.06(1.05)^{\star}$ & 0.0002 \\
\hline Blood glucose, mmol/L & $4.85(0.56)$ & $4.88(0.58)$ & $5.09(1.07) \dagger$ & 0.0007 \\
\hline$\gamma$-GT, units/L & $21(11,40)$ & $24(12,57)^{\star}$ & $26(13,55)$ & 0.0005 \\
\hline
\end{tabular}

CVD indicates cardiovascular disease; eGFR, estimated glomerular filtration rate calculated according to the Chronic Kidney Disease Epidemiology Collaboration equation formula, as described in reference $14 ; \gamma$-GT, $\gamma$-glutamyltransferase; HDL, highdensity lipoprotein; and THR, total-to-HDL cholesterol ratio. Office blood pressure was the average of 5 consecutive readings. Hypertension was an office blood pressure of $\geq 140 \mathrm{~mm} \mathrm{Hg}$ systolic, or $\geq 90 \mathrm{~mm} \mathrm{Hg}$ diastolic, or use of antihypertensive drugs. For $\gamma$-glutamyltransferase, values are geometric mean (interquartile range). Diabetes mellitus was a self-reported diagnosis, a condition mentioned on the death certificate or in records held by general practitioners or hospitals, antidiabetic drug intake, a fasting glucose level of at least $126 \mathrm{mg} / \mathrm{dL}$, or a random blood glucose at least $200 \mathrm{mg} / \mathrm{dL}$. $P$ values denote the significance of the differences in prevalence rates or means across thirds of the HF1 distribution.

Significance of the difference with the adjacent lower third: ${ }^{*} P \leq 0.05 ; \uparrow P \leq 0.01 ; \ddagger P \leq 0.001 ; \S P \leq 0.0001$. 
of cardiovascular disease, or diabetes mellitus increased with HF1. The proportions of women, smokers, and average heart rate did not differ across $\mathrm{HF1}$ categories $(P \geq 0.10)$.

\section{Incidence of Events}

Median follow-up was 6.1 years (5th to 95th percentile, 3.7-7.4). During 4552 person-years of follow-up, 35 participants died, 11 of cardiovascular disease, and 63 experienced a fatal or nonfatal cardiovascular event (14.4 events per 1000 person-years). Fatal or nonfatal cardiac event occurred in 45 participants (10.1 events per 1000 person-years) and coronary events in 22 (4.9 events per 1000 person-years). Table S3 lists the cause-specific cardiovascular mortality and morbidity for the study cohort.

\section{Risk Associated with HF1 Categories}

Crude rates of cardiovascular, cardiac, and coronary events increased across thirds of the HF1 distribution (Table S4; $P \leq 0.0032)$ with a similar trend for all-cause mortality $(P=0.057)$. The incidence of fatal combined with nonfatal cardiovascular $(P=0.014)$ and cardiac $(P=0.009)$ end points, standardized for sex and age group, increased across thirds of the HF1 distribution (Figure 1), whereas the trends for all-cause mortality and coronary events did not reach significance $(P \geq 0.10)$. For cardiovascular $(P=0.046)$ and cardiac $(P=0.028)$ events, the cumulative incidence ran a significantly higher course in the top compared with the low third of the HF1 distribution (Figure 2). These estimates were standardized to the means of the distributions of sex and age in the whole study population. Based on these results, the risk of cardiovascular and cardiac events was carried forward in multivariable-adjusted analyses.

\section{Multivariable-Adjusted Risk Associated with the HF1 Biomarker}

The step-down selection procedure identified sex, age, fasting blood sugar, smoking, and treatment with vasodilators as

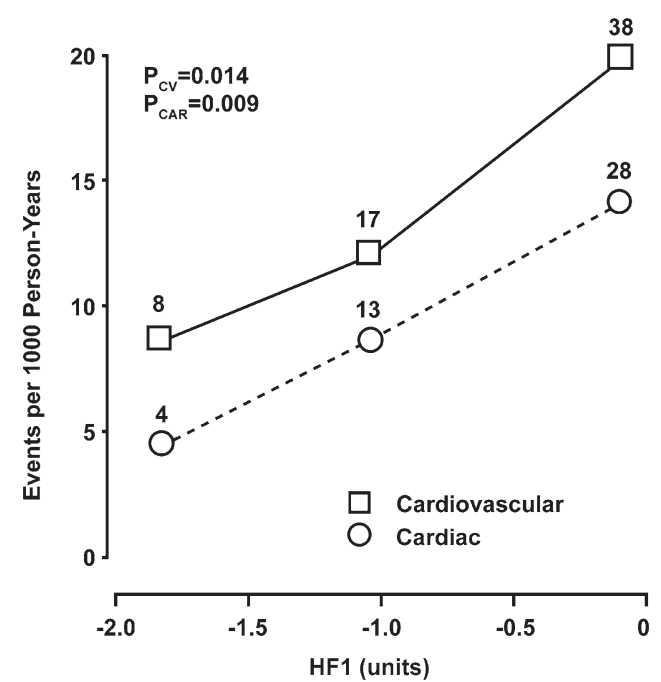

Figure 1. Incidence of fatal and nonfatal cardiovascular and cardiac events by tertiles of the distributions of the HF1 in 791 participants. Incidence rates were standardized for sex and age group ( $<40$ years, $40-60$ years, and $>60$ years) by the direct method. The number of end points contributing to the rates is shown. $P$ values are for trend. significant covariables of the risk of a cardiovascular or cardiac event (Table S5). Table 2 shows the multivariable-adjusted hazard ratios associated with a 1-SD increment in HF1. All Cox models complied with the proportional hazards assumption $(P \geq 0.056)$. In all 791 participants, HF1 was a significant predictor of fatal and nonfatal cardiovascular $(P=0.029)$ and cardiac events $(P=0.018)$, whereas systolic blood pressure was not $\left(P=0.85\right.$ and $P=0.66$, respectively). The generalized $R^{2}$ statistics for entering HF1 or systolic blood pressure (Table 2) as predictor in these models were 0.59 versus 0.01 for cardiovascular events and 0.69 versus 0.03 for cardiac events. Sensitivity analyses, from which we excluded 71 participants with previous cardiovascular disease (Table 2), or in all 791 participants with hypertension forced into the Cox models as additional covariable $(P$ values for HF1, $\leq 0.042$; data not shown) were confirmatory. Figure 3 shows the 5 -year absolute risk of a cardiovascular or cardiac event in relation to systolic blood pressure (Figure 3A and 3B) at different levels of HF1 or in relation to HF1 (Figure 3C and 3D) at different levels of systolic blood pressure. The analyses were standardized to the average of the distributions in the whole study population (mean or ratio) of sex, age, fasting plasma glucose, smoking, and treatment with vasodilators. Figure 3 illustrates that HF1, being significantly related to outcomes $(P \leq 0.033)$, was more informative than systolic pressure $(P \geq 0.54)$ in predicting cardiovascular and cardiac events over a 5-year span.

\section{Improvement of Prognostic Accuracy}

By maximizing Younden's index (Table 3), we determined optimal thresholds for HF1 in predicting cardiovascular or cardiac events. Sensitivity of the optimized thresholds ranged from $59 \%$ to $86 \%$ for cardiovascular events and from $53 \%$ to $58 \%$ for cardiac events. Specificity ranged from $46 \%$ to $75 \%$ and from $80 \%$ to $81 \%$, respectively. In all 791 participants (Table 4), both IDI and NRI reached significance for cardiovascular and cardiac events $(P \leq 0.006)$. In 720 participants free of cardiovascular disease at entry (Table 4), IDI and NRI were significant for cardiovascular events $(P<0.0001)$ and reached borderline significance for cardiac events $(P \leq 0.086)$.

\section{Discussion}

The key findings of our study were as follows: (i) over a follow-up period of $\approx 5$ years, the multidimensional urinary classifier HF1 predicted the incidence of fatal and nonfatal cardiovascular and cardiac events; (ii) after optimizing the HF1 thresholds, adding HF1 to Cox models, including baseline cardiovascular risk factors, significantly improved prognostic accuracy; (iii) HF1 was more informative than systolic blood pressure in the short-term prediction of cardiovascular and cardiac events. Our current findings are in line with a previous publication showing that in the same cohort, the early diastolic peak velocity of the mitral annulus $\left(e^{\prime}\right)$ predicted the incidence of fatal combined with nonfatal cardiovascular events over a 5 -year follow-up period. ${ }^{17}$ Over a similar follow-up, mild and moderate-to-severe diastolic left ventricular dysfunction predicted all-cause mortality in the Olmsted County study with hazard ratios amounting to 8.3 and 10.2, respectively $(P<0.001) .{ }^{18}$ As previously demonstrated in 
A

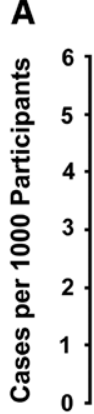

Cardiovascular Events

No. at risk by HF1 category

$\begin{array}{lllllll}\text { Low } & 264 & 262 & 260 & 250 & 221 & 175 \\ \text { Medium } & 263 & 260 & 257 & 248 & 223 & 174 \\ \text { High } & 264 & 260 & 252 & 240 & 206 & 156\end{array}$

B

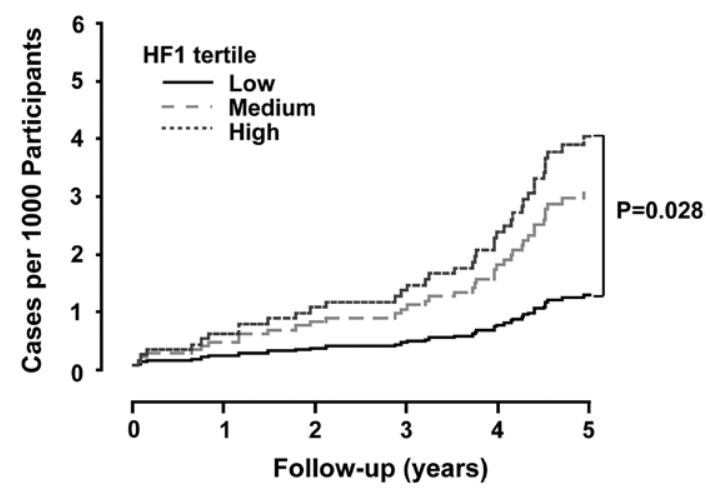

$\begin{array}{llllll}264 & 262 & 261 & 252 & 224 & 177 \\ 263 & 260 & 258 & 250 & 224 & 176 \\ 264 & 262 & 256 & 245 & 212 & 163\end{array}$

Figure 2. Cumulative incidence of cardiovascular (A) and cardiac end points (B) by thirds of the HF1 distribution. Estimates were standardized to the means of the distributions of sex and age in the whole study populations.

case-control ${ }^{6}$ and proof-of-concept ${ }^{7}$ studies, HF1 associates with diastolic left ventricular dysfunction.

Under physiological conditions, $\approx 70 \%$ of the urinary protein content originates from the kidney and the urinary tract, whereas the remaining $30 \%$ is derived from plasma. ${ }^{19}$ We hypothesized that the latter fraction may be informative on cardiac and cardiovascular disease. The multidimensional urinary classifier HF1 combines information on 85 urinary peptides, ${ }^{6}$ mainly upregulated and downregulated collagen fragments (Table S2). Patients with left ventricular dysfunction are characterized by a disturbed balance between collagen synthesis and degradation in the extracellular matrix of the myocardium and an increased interstitial deposition and cross-linking of type I collagen. ${ }^{20}$ The cardiac extracellular matrix is predominantly composed of fibrillar collagen type I $(85 \%)$ and type III (11\%). Furthermore, small amounts of collagen types IV and V codistribute with collagen I. The prime location of collagen $\mathrm{V}$ is at the fibril core and is important in nucleating collagen I-containing fibrils. ${ }^{21}$ The HF1 classifier also includes a downregulated peptide derived from the WW domain-binding protein 11 (Table S2) that remained statistically significant after adjustment for multiple testing. ${ }^{6}$
WBP11 is an inhibitor of protein phosphatase- $1 . .^{22}$ In cardiomyocytes, protein phosphatase-1 plays a key role in calcium handling and relaxation via dephosphorylation of phospholamban. ${ }^{23}$ In patients with heart failure, the activity of protein phosphatase-1 is enhanced, thereby delaying left ventricular relaxation. In line with this pathophysiological pathway, incident heart failure represented $33.3 \%$ and $46.7 \%$ of the cardiovascular and cardiac events, respectively. We also considered whether reducing the multidimensionality of classifiers, such as HF1, might be possible without losing information. However, we previously demonstrated that a higher number of peptides resulted in higher accuracy by reducing variability in the assessment of single components. ${ }^{24}$ In an additional analysis of the current data, we therefore tested a classifier based only on the 3 peptide biomarkers remaining significant after adjustment for multiple testing. ${ }^{6}$ As expected, this abridged classifier performed inferior to HF1 in diagnosing diastolic left ventricular dysfunction ${ }^{7}$ and in the prediction of cardiovascular and cardiac events (data not shown).

In population studies with long-term follow-up, blood pressure is the main driver of cardiovascular risk. ${ }^{25,26} \mathrm{In}$ our current study, HF1 largely outperformed systolic blood pressure

Table 2. Multivariable-Adjusted Hazard Ratios Associated With HF1 and Systolic Blood Pressure

\begin{tabular}{|c|c|c|c|c|c|c|c|}
\hline \multirow[b]{2}{*}{ End Points } & \multirow[b]{2}{*}{ Events/At Risk } & \multicolumn{3}{|c|}{ HF1 } & \multicolumn{3}{|c|}{ Systolic Blood Pressure } \\
\hline & & $\begin{array}{l}\text { Hazard Ratio } \\
(95 \% \mathrm{Cl})\end{array}$ & $P$ Value & $R^{2}$ & $\begin{array}{l}\text { Hazard Ratio } \\
(95 \% \mathrm{Cl})\end{array}$ & $P$ Value & $R^{2}$ \\
\hline \multicolumn{8}{|c|}{ Cardiovascular events } \\
\hline All participants & $63 / 791$ & $1.30(1.03-1.65)$ & 0.029 & 0.59 & $0.97(0.74-1.28)$ & 0.85 & 0.01 \\
\hline Free of CVD & $42 / 720$ & $1.39(1.03-1.87)$ & 0.034 & 0.59 & $1.00(0.72-1.39)$ & 0.98 & $<0.0001$ \\
\hline \multicolumn{8}{|l|}{ Cardiac events } \\
\hline All participants & $45 / 791$ & $1.39(1.06-1.84)$ & 0.018 & 0.69 & $0.93(0.67-1.29)$ & 0.66 & 0.03 \\
\hline Free of CVD & $32 / 720$ & $1.38(0.98-1.95)$ & 0.066 & 0.44 & $0.97(0.66-1.40)$ & 0.85 & 0.01 \\
\hline
\end{tabular}



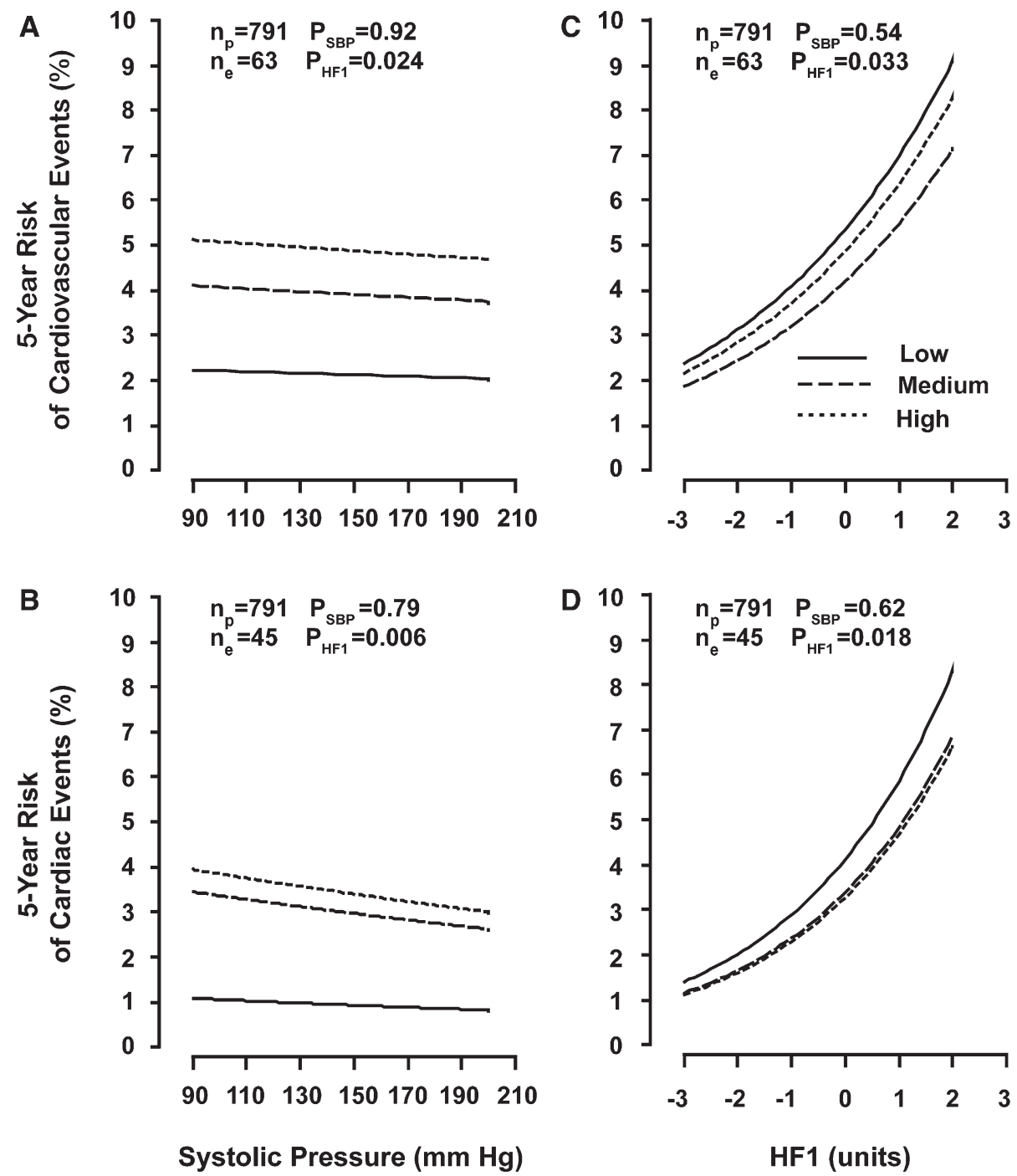

Figure 3. Five-year absolute risk of cardiovascular and cardiac events in relation to systolic blood pressure (A, B) at different categories of HF1 and in relation to HF1 (C, D) at different levels of systolic blood pressure. The analyses were standardized to the average of the distributions in the whole study population (mean or ratio) of sex, age, fasting plasma glucose, smoking, treatment with vasodilators (calcium-channel blockers or $\alpha$-blockers). In $\mathbf{A}$ and $\mathbf{B}$, the risk functions span the 5 th to 95th percentile interval of systolic blood pressure and correspond to the low, medium, and high categories of HF1. In C and D, the risk functions span the 5th to 95th percentile intervals of HF1 and correspond to the low ( $<33$ th percentile), medium (33-66th percentile), and high ( $>66$ th percentile) categories of systolic blood pressure. $P$ values are for the independent effect of HF1 $\left(P_{\mathrm{HF} 1}\right)$ and systolic blood pressure $\left(p_{\mathrm{SBP}}\right) \cdot n_{\mathrm{P}}$ and $n_{\mathrm{e}}$ indicate the number of participants at risk and the number of events.

in the prediction of cardiovascular and cardiac complications. These observations cannot be attributed to the quality of our blood pressure measurements, as exemplified by the absence of terminal digit and number preference. Several investigators have reported that single blood pressure measurements predicted the risk of cardiovascular disease over a follow-up

Table 3. Optimized HF1 Thresholds in the Prediction of Cardiovascular and Cardiac Events

\begin{tabular}{|c|c|c|c|c|c|c|c|}
\hline End Points & $\begin{array}{c}\text { Optimal } \\
\text { Discrimination Limit }\end{array}$ & $\begin{array}{l}\text { Hazard Ratio } \\
\qquad(95 \% \mathrm{Cl})\end{array}$ & Sensitivity, \% & Specificity, \% & $\begin{array}{l}\text { Positive Predictive } \\
\text { Value, } \%\end{array}$ & $\begin{array}{l}\text { Negative Predictive } \\
\text { Value, } \%\end{array}$ & $\begin{array}{c}\text { Misclassification } \\
\text { Rate, } \%\end{array}$ \\
\hline \multicolumn{8}{|l|}{ Cardiovascular events } \\
\hline All participants $(\mathrm{n}=791)$ & -0.50 & $3.98(2.41-6.57)$ & 59 & 75 & 17 & 96 & 26 \\
\hline Free of CVD $(n=720)$ & -1.22 & $4.84(2.04-11.5)$ & 86 & 46 & 9 & 98 & 52 \\
\hline \multicolumn{8}{|l|}{ Cardiac events } \\
\hline All participants $(\mathrm{n}=791)$ & -0.36 & $5.01(2.77-9.05)$ & 58 & 80 & 15 & 97 & 22 \\
\hline Free of CVD $(n=720)$ & -0.36 & $4.58(2.29-9.18)$ & 53 & 81 & 12 & 97 & 20 \\
\hline
\end{tabular}

The optimal discrimination limit was obtained by maximizing Younden's index (the maximum of sensitivity plus specificity minus 1). Hazard ratios (95\% confidence interval) present the risk associated with exceeding the biomarker threshold. The hazard ratios were significant $(P \leq 0.0003)$. 
Table 4. Integrated Discrimination Improvement and Net Reclassification Improvement by Adding HF1 to the Basic Model Including Covariables

\begin{tabular}{|c|c|c|c|c|c|c|}
\hline \multirow[b]{2}{*}{ End Points } & \multicolumn{3}{|c|}{$\begin{array}{l}\text { Integrated Discrimination } \\
\text { Improvement }\end{array}$} & \multicolumn{3}{|c|}{$\begin{array}{l}\text { Net Reclassification } \\
\text { Improvement }\end{array}$} \\
\hline & IDI, \% & $\mathrm{Cl}, \%$ & $P$ Value & NRI, \% & $\mathrm{Cl}, \%$ & $P$ Value \\
\hline \multicolumn{7}{|l|}{ Cardiovascular events } \\
\hline All participants ( $\mathrm{n=791)}$ & 1.89 & $0.54-3.24$ & 0.006 & 49.9 & $24.6-75.2$ & 0.0001 \\
\hline Free of CVD $(n=720)$ & 2.13 & $1.33-2.93$ & $<0.0001$ & 63.8 & $41.3-86.2$ & $<0.0001$ \\
\hline \multicolumn{7}{|l|}{ Cardiac events } \\
\hline All participants ( $\mathrm{n=791)}$ & 2.00 & $0.60-3.40$ & 0.005 & 46.1 & $16.5-75.8$ & 0.002 \\
\hline Free of CVD $(\mathrm{n}=720)$ & 1.34 & $0.61-2.73$ & 0.061 & 31.0 & -4.37 to 66.3 & 0.086 \\
\hline
\end{tabular}

The basic reference models included as covariables sex, age, fasting plasma glucose, smoking, and treatment with vasodilators. The IDI is the difference between the discrimination slopes of basic models and basic models extended with HF1. The discrimination slope is the difference in predicted probabilities (\%) between cases and controls. Controls are participants without incident cardiovascular or cardiac disease. The NRI is the sum of the net percentages of subjects reclassified correctly in cases and controls. Cl indicates confidence interval; IDI, integrated discrimination improvement; and NRI, net reclassification improvement.

period of 15 to 50 years, but also that the impact of blood pressure diminished with increasing duration of follow-up. ${ }^{27-34}$ The strongest evidence in this regards comes from the Framingham Heart Study. ${ }^{34}$ Vasan and coworkers used sex- and age-specific multivariable Cox regression to evaluate the association of current blood pressure (at baseline), recent antecedent blood pressure (average of readings for all available examinations 1-10 years before baseline), and remote antecedent blood pressure (average for all available examinations 11-20 years before baseline) with the 10-year risk of new-onset cardiovascular disease in 2313 Framingham Study participants. During follow-up, cardiovascular disease occurred in 899 participants. In multivariable-adjusted models, recent and remote antecedent blood pressure predicted the risk of cardiovascular disease incrementally over current blood pressure. This observation was consistent in multiple subgroups: women $(n=1403)$ and men $(\mathrm{n}=910)$ and 3 age strata $(60-69,70-79$, and $\geq 80$ years).$^{34}$ Explanations offered by the Framingham investigators were that antecedent blood pressure is a forerunner of cardiovascular target organ damage, which is on the path to hard cardiovascular complications, and that the relation between cardiovascular risk and blood pressure might be weakened by the initiation of antihypertensive drug treatment. ${ }^{34}$ Our current findings remained consistent after exclusion of participants with a history of cardiovascular disease. Similarly, estimates of the hazard ratios remained confirmatory if we forced hypertension as covariable in the Cox models or if we limited the analyses to participants untreated for hypertension at baseline (data not shown).

Use of vasodilators, calcium-channel blockers or $\alpha$-blockers, at baseline was among the significant predictors of cardiovascular or cardiac events, for which our analyses were adjusted. Although resulting from an observational study, our findings are not surprising in view of the results of the Antihypertensive and Lipid-Lowering Treatment to Prevent Heart Attack Trial (ALLHAT). ${ }^{35-37}$ In ALLHAT, use of doxazosin or amlodipine, compared with chlorthalidone was associated with an increased risk of combined cardiovascular disease. This secondary end point was driven by congestive heart failure ${ }^{35-37}$ and coronary revascularization, ${ }^{35-37}$ and for doxazosin also by hospitalized or treated angina pectoris. ${ }^{37}$ Diuretics, $\beta$-blockers, angiotensin-converting enzyme inhibitors, and angiotensin type-1 receptor blockers are drug classes used in the primary and secondary prevention of cardiovascular complications, in particular heart failure, but in our current study, use of these drug classes at baseline did not predict cardiovascular or cardiac complications.

To our knowledge, there is no other population-based study that explored the value of the urinary proteome in predicting cardiovascular or cardiac complications. Nevertheless, our study must be interpreted within the context of its limitations. First, the sample size and number of events were substantially smaller than, for instance, in the Framingham Heart Study. ${ }^{34}$ This might explain why we could not show any significant prognostic value of HF1 in relation to the incidence of mortality or coronary events. Second, our current study with a median follow-up of 6.1 years does not allow to compare the prognostic value of HF1 and blood pressure over a longer follow-up. Third, we did not assess the incremental predictive value of HF1 with other biomarkers of risk, such as high-sensitivity C-reactive protein $^{38}$ or high-sensitivity troponin T. ${ }^{39}$

\section{Perspectives}

Our current study demonstrated that the urinary proteome, but not systolic pressure, predicts incident cardiovascular and cardiac disease over a 5-year period and thereby confirmed the diagnostic utility of the urinary proteomic signature ${ }^{6-8}$ Further prospective studies should underpin its use in clinical practice compared with other biomarkers over varying intervals of follow-up in relation to different end points. A previous publication in the same cohort demonstrated that the early diastolic peak velocity of the mitral annulus $\left(e^{\prime}\right)$ predicts the incidence of fatal combined with nonfatal cardiovascular events over a 5-year follow-up period. ${ }^{17}$ When we introduced both HF1 and $e^{\prime}$ in multivariable-adjusted models (62 cardiovascular and 44 cardiac events in 776 participants who underwent an assessment of their diastolic left ventricular function; data not shown), both were predictive, albeit with borderline $P$ values $(0.020 \leq P \leq 0.097)$, reflecting complementarity of information. 
However, for screening purposes, HF1 is less costly and labor-intensive than echocardiography and therefore preferable. Having the urinary proteome confirmed as a short-term predictor of adverse outcomes might allow the timely initiation of preventive or therapeutic measures. On the other hand, quality-of-life of patients confronted with a prognostically adverse urinary proteomic signature and cost-effectiveness remain issues of concern.

\section{Acknowledgments}

Linda Custers, Annick De Soete, Marie-Jeanne Jehoul, Daisy Thijs, Hanne Truyens, and Renilde Wolfs provided expert technical and clerical assistance.

\section{Sources of Funding}

The European Union (grants HEALTH-2011.2.4.2-2-EUMASCARA, HEALTH-F7-305507 HOMAGE, and the European Research Council Advanced Researcher Grant-2011-294713EPLORE) gave support to the Studies Coordinating Centre, Leuven, Belgium. The Fonds voor Wetenschappelijk Onderzoek Vlaanderen, Ministry of the Flemish Community, Brussels, Belgium (G.0881.13 and G.0880.13), also supported the Flemish Study on Environment, Genes and Health Outcomes (FLEMENGHO) study.

\section{Disclosures}

T. Koeck and P. Zürbig are employees of Mosaiques-Diagnostics $\mathrm{GmbH}$. H. Mischak is the cofounder and co-owner of Mosaiques Diagnostics GmbH (http://mosaiques-diagnostics.de/diapatpcms/mosaiquescms/front_content.php?idcat=161) and Diapat GmbH (http:// www.diapat.com/DiaPat-Diagnostik/diapat-en), Hannover, Germany. The other authors did not declare a conflict of interest.

\section{References}

1. Mischak H, Coon JJ, Novak J, Weissinger EM, Schanstra JP, Dominiczak AF. Capillary electrophoresis-mass spectrometry as a powerful tool in biomarker discovery and clinical diagnosis: an update of recent developments. Mass Spectrom Rev. 2009;28:703-724. doi: 10.1002/mas.20205.

2. Zürbig P, Jerums G, Hovind P, Macisaac RJ, Mischak H, Nielsen SE, Panagiotopoulos S, Persson F, Rossing P. Urinary proteomics for early diagnosis in diabetic nephropathy. Diabetes. 2012;61:3304-3313. doi: $10.2337 / \mathrm{db} 12-0348$.

3. Theodorescu D, Wittke S, Ross MM, Walden M, Conaway M, Just I, Mischak H, Frierson HF. Discovery and validation of new protein biomarkers for urothelial cancer: a prospective analysis. Lancet Oncol. 2006;7:230-240. doi: 10.1016/S1470-2045(06)70584-8.

4. Theodorescu D, Fliser D, Wittke S, Mischak H, Krebs R, Walden M, Ross M, Eltze E, Bettendorf O, Wulfing C, Semjonow A. Pilot study of capillary electrophoresis coupled to mass spectrometry as a tool to define potential prostate cancer biomarkers in urine. Electrophoresis. 2005;26:2797-2808. doi: 10.1002/elps.200400208.

5. von Zur Muhlen C, Schiffer E, Zuerbig P, Kellmann M, Brasse M, Meert N, Vanholder RC, Dominiczak AF, Chen YC, Mischak H, Bode C, Peter K. Evaluation of urine proteome pattern analysis for its potential to reflect coronary artery atherosclerosis in symptomatic patients. J Proteome Res. 2009;8:335-345. doi: 10.1021/pr800615t.

6. Kuznetsova T, Mischak H, Mullen W, Staessen JA. Urinary proteome analysis in hypertensive patients with left ventricular diastolic dysfunction. Eur Heart J. 2012;33:2342-2350. doi: 10.1093/eurheartj/ehs 185.

7. Zhang Z, Staessen JA, Thijs L, Gu Y, Liu Y, Jacobs L, Koeck T, Zürbig P, Mischak H, Kuznetsova T. Left ventricular diastolic function in relation to the urinary proteome: a proof-of-concept study in a general population. Int J Cardiol. 2014;176:158-165. doi: 10.1016/j.ijcard.2014.07.014.

8. Gu YM, Thijs L, Liu YP, Zhang Z, Jacobs L, Koeck T, Zürbig P, Lichtinghagen R, Brand K, Kuznetsova T, Olivi L, Verhamme P, Delles $\mathrm{C}$, Mischak H, Staessen JA. The urinary proteome as correlate and predictor of renal function in a population study. Nephrol Dial Transplant. 2014;29:2260-2268. doi: 10.1093/ndt/gfu234.

9. Li Y, Zagato L, Kuznetsova T, Tripodi G, Zerbini G, Richart T, Thijs L, Manunta P, Wang JG, Bianchi G, Staessen JA. Angiotensin-converting enzyme I/D and alpha-adducin Gly460Trp polymorphisms: from angiotensin-converting enzyme activity to cardiovascular outcome. Hypertension. 2007;49:1291-1297. doi: 10.1161/HYPERTENSIONAHA.106.085498.

10. Staessen JA, Wang JG, Brand E, Barlassina C, Birkenhäger WH, Herrmann SM, Fagard R, Tizzoni L, Bianchi G. Effects of three candidate genes on prevalence and incidence of hypertension in a Caucasian population. J Hypertens. 2001;19:1349-1358.

11. Mischak H, Vlahou A, Ioannidis JP. Technical aspects and inter-laboratory variability in native peptide profiling: the CE-MS experience. Clin Biochem. 2013;46:432-443.

12. Staessen J, Bulpitt CJ, Fagard R, Joossens JV, Lijnen P, Amery A. Familial aggregation of blood pressure, anthropometric characteristics and urinary excretion of sodium and potassium-a population study in two Belgian towns. J Chronic Dis. 1985;38:397-407.

13. Kuznetsova T, Staessen JA, Kawecka-Jaszcz K, Babeanu S, Casiglia E, Filipovsky J, Nachev C, Nikitin Y, Peleskã J, O'Brien E. Quality control of the blood pressure phenotype in the European Project on Genes in Hypertension. Blood Press Monit. 2002;7:215-224.

14. Levey AS, Stevens LA, Schmid CH, Zhang YL, Castro AF III, Feldman HI, Kusek JW, Eggers P, Van Lente F, Greene T, Coresh J; CKD-EPI (Chronic Kidney Disease Epidemiology Collaboration). A new equation to estimate glomerular filtration rate. Ann Intern Med. 2009;150:604-612.

15. Expert Committee on the Diagnosis and Classification of Diabetes Mellitus. Report of the expert committee on the diagnosis and classification of diabetes mellitus. Diabet Care. 2003;26(suppl 1):S5-S20.

16. Pencina MJ, D'Agostino RB Sr, D'Agostino RB Jr, Vasan RS. Evaluating the added predictive ability of a new marker: from area under the ROC curve to reclassification and beyond. Stat Med. 2008;27:157-172; discussion 207. doi: 10.1002/sim.2929.

17. Kuznetsova T, Thijs L, Knez J, Herbots L, Zhang Z, Staessen JA. Prognostic value of left ventricular diastolic dysfunction in a general population. $J$ Am Heart Assoc. 2014;3:e000789. doi: 10.1161/JAHA.114.000789.

18. Redfield MM, Jacobsen SJ, Burnett JC Jr, Mahoney DW, Bailey KR, Rodeheffer RJ. Burden of systolic and diastolic ventricular dysfunction in the community: appreciating the scope of the heart failure epidemic. JAMA. 2003;289:194-202.

19. Pieper R, Gatlin CL, McGrath AM, Makusky AJ, Mondal M, Seonarain M, Field E, Schatz CR, Estock MA, Ahmed N, Anderson NG, Steiner $\mathrm{S}$. Characterization of the human urinary proteome: a method for highresolution display of urinary proteins on two-dimensional electrophoresis gels with a yield of nearly 1400 distinct protein spots. Proteomics. 2004;4:1159-1174. doi: 10.1002/pmic.200300661.

20. Burlew BS, Weber KT. Cardiac fibrosis as a cause of diastolic dysfunction. Herz. 2002;27:92-98.

21. Kadler KE, Hill A, Canty-Laird EG. Collagen fibrillogenesis: fibronectin, integrins, and minor collagens as organizers and nucleators. Curr Opin Cell Biol. 2008;20:495-501. doi: 10.1016/j.ceb.2008.06.008.

22. Llorian M, Beullens M, Andrés I, Ortiz JM, Bollen M. SIPP1, a novel premRNA splicing factor and interactor of protein phosphatase-1. Biochem J. 2004;378(Pt 1):229-238. doi: 10.1042/BJ20030950.

23. Neumann J. Altered phosphatase activity in heart failure, influence on Ca2+ movement. Basic Res Cardiol. 2002;97(suppl 1):I91-I95.

24. Dakna M, Harris K, Kalousis A, Carpentier S, Kolch W, Schanstra JP, Haubitz M, Vlahou A, Mischak H, Girolami M. Addressing the challenge of defining valid proteomic biomarkers and classifiers. $B M C$ Bioinformatics. 2010;11:594. doi: 10.1186/1471-2105-11-594.

25. Lewington S, Clarke R, Qizilbash N, Peto R, Collins R; Prospective Studies Collaboration. Age-specific relevance of usual blood pressure to vascular mortality: a meta-analysis of individual data for one million adults in 61 prospective studies. Lancet. 2002;360:1903-1913.

26. Li Y, Wei FF, Thijs L, et al; International Database on Ambulatory blood pressure in relation to Cardiovascular Outcomes (IDACO) Investigators. Ambulatory hypertension subtypes and 24-hour systolic and diastolic blood pressure as distinct outcome predictors in 8341 untreated people recruited from 12 populations. Circulation. 2014;130:466-474. doi: 10.1161/CIRCULATIONAHA.113.004876.

27. Gordon T, Sorlie P, Kannel WB. Problems in the assessment of blood pressure: the Framingham Study. Int J Epidemiol. 1976;5:327-334.

28. Prentice RL, Shimizu Y, Lin CH, Peterson AV, Kato H, Mason MW, Szatrowski TP. Serial blood pressure measurements and cardiovascular disease in a Japanese cohort. Am J Epidemiol. 1982;116:1-28.

29. Harris T, Cook EF, Kannel W, Schatzkin A, Goldman L. Blood pressure experience and risk of cardiovascular disease in the elderly. Hypertension. 1985;7:118-124. 
30. Pekkanen J, Tervahauta M, Nissinen A, Karvonen MJ. Does the predictive value of baseline coronary risk factors change over a 30-year follow-up? Cardiology. 1993;82:181-190.

31. Welin L, Eriksson H, Larsson B, Svärdsudd K, Wilhelmsen L, Tibblin G. Risk factors for coronary heart disease during 25 years of follow-up. The study of men born in 1913. Cardiology. 1993;82:223-228.

32. Wannamethee SG, Shaper AG, Whincup PH, Walker M. Role of risk factors for major coronary heart disease events with increasing length of follow up. Heart. 1999;81:374-379.

33. McCarron P, Smith GD, Okasha M, McEwen J. Blood pressure in young adulthood and mortality from cardiovascular disease. Lancet. 2000;355:1430-1431. doi: 10.1016/S0140-6736(00)02146-2.

34. Vasan RS, Massaro JM, Wilson PW, Seshadri S, Wolf PA, Levy D, D’ Agostino RB; Framingham Heart Study. Antecedent blood pressure and risk of cardiovascular disease: the Framingham Heart Study. Circulation. 2002;105:48-53.

35. The ALLHAT Officers and Coordinators for the ALLHAT Collaborative Research Group. Major cardiovascular events in hypertensive patients randomized to doxazosin vs chlorthalidone: the antihypertensive and lipidlowering treatment to prevent heart attack trial (ALLHAT). ALLHAT Collaborative Research Group. JAMA. 2000;283:1967-1975.
36. The ALLHAT Officers and Coordinators for the ALLHAT Collaborative Research Group. Major outcomes in high-risk hypertensive patients randomized to angiotensin-converting enzyme inhibitor or calcium channel blocker vs diuretic: the Antihypertensive and Lipid-Lowering Treatment to Prevent Heart Attack Trial (ALLHAT) JAMA. 2002;288:2981-2997.

37. ALLHAT Officers and Coordinators for the ALLHAT Collaborative Research Group. Diuretic versus $\alpha$-blocker as first step antihypertensive therapy. Final results from the Antihypertensive and Lipid-Lowering Treatment to Prevent Heart Attack Trial (ALLHAT). Hypertension. 2003;42:239-246.

38. van Wijk DF, Boekholdt SM, Wareham NJ, Ahmadi-Abhari S, Kastelein JJ, Stroes ES, Khaw KT. C-reactive protein, fatal and nonfatal coronary artery disease, stroke, and peripheral artery disease in the prospective EPIC-Norfolk cohort study. Arterioscler Thromb Vasc Biol. 2013;33:2888-2894. doi: 10.1161/ATVBAHA.113.301736.

39. Xanthakis V, Enserro DM, Murabito JM, Polak JF, Wollert KC, Januzzi JL, Wang TJ, Tofler G, Vasan RS. Ideal cardiovascular health: associations with biomarkers and subclinical disease and impact on incidence of cardiovascular disease in the Framingham Offspring Study. Circulation. 2014;130:1676-1683. doi: 10.1161/CIRCULATIONAHA.114.009273.

\section{Novelty and Significance}

\section{What Is New?}

- In a previous cross-sectional study, we identified a multidimensional urinary peptide-based classifier (HF1), which was associated with left ventricular dysfunction. In randomly recruited Flemish people, we investigated whether HF1 predicts cardiovascular end points over and beyond traditional risk factors.

\section{What Is Relevant?}

- Over a 5 year follow-up period, the standardized and multivariable-adjusted hazard ratios relating cardiovascular $(n=63)$ and cardiac $(n=45)$ events with HF1 were 1.30 and $1.39(P \leq 0.029)$, respectively, whereas those with systolic pressure were around unity $(P \geq 0.66)$.

- The diagnostic improvement obtained by adding optimized HF1 thresholds to Cox models including classical cardiovascular risk factors, including systolic blood pressure, was significant $(P \leq 0.006)$.

\section{Summary}

Over $\approx 5$ years of follow-up, the urinary proteome, but not systolic pressure, predicted incident cardiovascular disease. Further prospective studies should confirm its diagnostic utility compared with other biomarkers over varying intervals of follow-up in relation to different end points. Having the urinary proteome confirmed as a short-term predictor of adverse outcomes might allow the timely initiation of preventive or therapeutic measures. 


\section{HYPERTENSION}

\section{Supplementary Appendix}

This appendix is part of the original submission and has been peer reviewed.

Supplement to The Urinary Proteome and Systolic Blood Pressure as Predictors of 5-Year Cardiovascular and Cardiac Outcomes in a General Population. Hypertension 2015;

published online 12 May 2015 (DOI: 10.1161/HYPERTENSIONAHA.115.05296). 


\section{Expanded Methods}

\section{Urinary Proteomics}

Aliquots of urine were stored at $-80^{\circ} \mathrm{C}$. Urine $(0.7 \mathrm{~mL})$ was thawed immediately before analysis and diluted with $0.7 \mathrm{~mL}$ of $2 \mathrm{M}$ urea, $10 \mathrm{mM} \mathrm{NH}_{4} \mathrm{OH}$ containing $0.02 \%$ SDS. 1 To remove higher molecular mass proteins, such as albumin and immunoglobulin $G$, the samples were ultrafiltered using Centrisart ultracentrifugation devices (20 kDa MWCO; Sartorius, Göttingen, Germany) at 2,000 g relative centrifugal force until $1.1 \mathrm{~mL}$ of filtrate was obtained. This filtrate was then applied onto a PD-10 desalting column (GE Healthcare, Uppsala, Sweden) equilibrated in $0.01 \% \mathrm{NH}_{4} \mathrm{OH}$ in $\mathrm{HPLC}$-grade $\mathrm{H}_{2} \mathrm{O}$ (Roth, Germany) to decrease matrix effects by removing urea, electrolytes, and salts, and to enrich peptides. Finally, all samples were lyophilized, stored at $4{ }^{\circ} \mathrm{C}$, and suspended in HPLC-grade $\mathrm{H}_{2} \mathrm{O}$ shortly before capillary electrophoresis coupled with mass spectrometry (CE-MS).

As described in detail elsewhere, ${ }^{2}$ CE-MS analyses were performed using a P/ACE MDQ capillary electrophoresis system (Beckman Coulter, Brea, CA) on-line coupled to a micrOTOF MS (Bruker Daltonic, Bremen, Germany). The ESI sprayer (Agilent Technologies, Palo Alto, CA) was grounded, and the ion spray interface potential was set between -4 and $-4.5 \mathrm{kV}$. Data acquisition and mass spectrometry acquisition methods were automatically controlled by the capillary electrophoresis via contact-close-relays. Spectra were accumulated every 3 seconds, over a range of charge states (m/z) 350 to 3000 . Previous publications described the accuracy, precision, selectivity, sensitivity, reproducibility, and stability of the CE-MS measurements in detail. 2,3

Mass spectra were processed using MosaiquesVisu software, including peak picking, deconvolution and deisotoping. ${ }^{4}$ Migration time and peak intensity were normalized using internal peptide standards. 5 These fragments result from normal biological processes and 
appear to be unaffected by any disease state studied to date based on over 20,000 samples in the Mosaiques database. 6 The resulting list of peaks characterizes each peptide by its molecular mass, normalized capillary electrophoresis migration time, and normalized signal intensity. All detected peptides were deposited, matched, and annotated in a Microsoft SQL database, allowing further analysis and comparison of multiple patient groups. Peptide fragments were combined into a single summary variable, using the support-vector machine based MosaCluster software, version 1.6.5.

In the present study, we used the previously published multidimensional classifier, which is associated with decreased left ventricular function and which combines information from 85 peptide fragments identified in 19 patients with diastolic LV dysfunction and 19 controls. ${ }^{7}$ The classifier established by SVM modelling allows the classification of samples in the high dimensional data space. MosaCluster calculates classification scores based on the amplitudes of all HF1 biomarkers in the different samples. Classification is performed by determining the Euclidian distance (defined as the SVM classification score) of the vector to a maximal margin separating hyperplane. The SVM classifier uses the log transformed intensities of the urinary peptides as coordinates in an $\mathrm{N}$-dimensional space. For HF1, $\mathrm{N}$ equals to 85 . The SVM classifier then builds an $\mathrm{N}-1$ dimensional hyperplane that spans this space by performing a quadratic programming optimization of a Lagrangian, using the training labels only while allowing for samples to lie at the wrong side of the plane. For such mistakes in classification the SVM introduces a cost parameter C. Because non-separable problems in low dimensions may be separable in higher dimensions, the SVM uses the Kernel-trick to transform the data to a higher dimensional space. MosaCluster uses the standard radial basis functions as kernel. These functions are just Gaussians with the parameter gamma controlling their width. The optimal parameters $C$ and gamma are found via cross validation error estimation, using a lattice build by different values of these two 
parameters. SVMs are frequently implemented in data mining software. In particular, the kernlab cran R package is a versatile tool for building SVM based-classifiers. 


\section{References}

1. Theodorescu D, Fliser D, Wittke S, Mischak H, Krebs R, Walden M, Ross M, Eltze E, Bettendorf O, Wulfing C, Semjonow A. Pilot study of capillary electrophoresis coupled to mass spectrometry as a tool to define potential prostate cancer biomarkers in urine. Electrophoresis. 2005;26:2797-2808.

2. Mischak H, Vlahou A, loannidis JP. Technical aspects and inter-laboratory variability in native peptide profiling: the CE-MS experience. Clin Biochem. 2013;46:432-443.

3. Haubitz M, Good DM, Woywodt A, Haller H, Rupprecht H, Theodorescu D, Dakna M, Coon JJ, Mischak $\mathrm{H}$. Identification and validation of urinary biomarkers for differential diagnosis and evaluation of therapeutic intervention in anti-neutrophil cytoplasmic antibody-associated vasculitis. Mol Cell Proteomics. 2009;8:2296-2307.

4. Neuhoff NV, Kaiser T, Wittke S, Krebs R, Pitt A, Burchard A, Sundmacher A, Schlegelberger B, Kolch W, Mischak H. Mass spectrometry for the detection of differentially expressed proteins : a comparison of surface-enhanced laser desorption/ionization and capillary electrophoresis/mass spectrometry. Rapid Commun Mass Spectrom. 2004;18:149-156.

5. Jantos-Siwy J, Schiffer E, Brand K, Schumann G, Rossing K, Delles C, Mischak H, Metzger J. Quantitative urinary proteome analysis for biomarker evaluation in chronic kidney disease. J Proteome Res. 2009;8:268-281.

6. Coon JJ, Zürbig P, Dakna M, Dominiczak AF, Decramer S, Fliser D, Frommberger M, Golovko I, Good DM, Herget-Rosenthal S, Jankowski J, Julian BA, Kellmann M, Kolch W, Massy Z, Novak J, Rossing K, Schanstra JP, Schiffer E, Theodorescu D, Vanholder R, 
Weissinger EM, Mischak H, Schmitt-Kopplin P. CE-MS analysis of the human urinary proteome for biomarker discovery and disease diagnostics. Proteomics Clin Appl. 2008;2:964.

7. Kuznetsova T, Mischak H, Mullen W, Staessen JA. Urinary proteome analysis in hypertensive patients with left ventricular diastolic dysfunction. Eur Heart J. 2012;33:2342-2350. 
Table S1. List of 85 Peptides Included in the HF1 Biomarker

\begin{tabular}{|c|c|c|c|c|c|c|c|c|}
\hline \multicolumn{3}{|c|}{ Peptide } & \multicolumn{2}{|c|}{ Cases } & \multicolumn{2}{|c|}{ Controls } & \multirow[b]{2}{*}{$\mathrm{R}$} & \multirow[b]{2}{*}{$\begin{array}{c}P \text {-value } \\
\text { (Unadjusted) }\end{array}$} \\
\hline ID & $\begin{array}{l}\text { Mass } \\
(\mathrm{Da})\end{array}$ & $\begin{array}{l}\text { CE Time } \\
(\min )\end{array}$ & $\%$ & MA & $\%$ & MA & & \\
\hline 81272 & 2211.98 & 33.23 & 0 & 0 & 0.42 & 2.67 & 0 & 1.99E-03 \\
\hline 129821 & 3333.36 & 19.42 & 0 & 0 & 0.47 & 2.39 & 0 & 8.72E-04 \\
\hline 8725 & 949.4 & 25.79 & 0.05 & 1.94 & 0.63 & 2.28 & 0.067 & $2.22 \mathrm{E}-04$ \\
\hline 123106 & 3130.43 & 30.82 & 0.05 & 1.98 & 0.47 & 2.63 & 0.080 & 2.57E-03 \\
\hline 1577 & 840.41 & 23.17 & 0.05 & 1.65 & 0.47 & 1.85 & 0.095 & $3.29 E-03$ \\
\hline 103493 & 2658.22 & 19.5 & 0.05 & 3.36 & 0.47 & 3.29 & 0.109 & 4.71E-03 \\
\hline 44146 & 1518.6 & 19.37 & 0.11 & 1.91 & 0.58 & 2.49 & 0.145 & 1.33E-03 \\
\hline 4845 & 900.27 & 43.66 & 0.16 & 1.55 & 0.63 & 2.44 & 0.161 & $1.33 \mathrm{E}-03$ \\
\hline 37610 & 1421.59 & 38.71 & 0.11 & 1.73 & 0.53 & 1.87 & 0.192 & 6.07E-03 \\
\hline 83441 & 2248.97 & 33.69 & 0.11 & 3.45 & 0.53 & 3.56 & 0.201 & $4.88 \mathrm{E}-03$ \\
\hline 74703 & 2087.84 & 19.42 & 0.11 & 2.64 & 0.53 & 2.7 & 0.203 & 6.76E-03 \\
\hline 101157 & 2616.16 & 28.39 & 0.11 & 1.97 & 0.53 & 1.98 & 0.206 & 6.76E-03 \\
\hline 103022 & 2649.2 & 34.85 & 0.16 & 2.52 & 0.68 & 2.56 & 0.232 & $2.50 \mathrm{E}-03$ \\
\hline 57360 & 1734.66 & 19.9 & 0.16 & 2.2 & 0.58 & 2.24 & 0.271 & 1.03E-02 \\
\hline 46091 & 1554.66 & 28.59 & 0.16 & 2.08 & 0.53 & 2.24 & 0.280 & 1.18E-02 \\
\hline 32022 & 1319.58 & 20.89 & 0.21 & 1.99 & 0.58 & 2.21 & 0.326 & 1.57E-02 \\
\hline 102269 & 2638.18 & 28.42 & 0.26 & 2.3 & 0.68 & 2.49 & 0.353 & 1.26E-02 \\
\hline 82708 & 2235.04 & 34.17 & 0.32 & 2.57 & 0.84 & 2.68 & 0.365 & $2.53 \mathrm{E}-03$ \\
\hline 188895 & 11967.55 & 20.47 & 0.26 & 2.68 & 0.63 & 2.94 & 0.376 & $9.50 \mathrm{E}-03$ \\
\hline 98089 & 2559.18 & 19.41 & 0.32 & 2.97 & 0.84 & 3 & 0.377 & 3.76E-03 \\
\hline 138143 & 3593.47 & 20.2 & 0.26 & 2.67 & 0.68 & 2.68 & 0.381 & $1.50 \mathrm{E}-02$ \\
\hline 167786 & 4771.07 & 20.2 & 0.37 & 2.74 & 0.79 & 3.13 & 0.410 & 4.34E-03 \\
\hline 61984 & 1835.71 & 19.91 & 0.53 & 2.64 & 1 & 3.12 & 0.448 & 1.33E-04 \\
\hline 46369 & 1560.7 & 29.79 & 0.32 & 2.78 & 0.68 & 2.84 & 0.461 & 2.27E-02 \\
\hline 143947 & 3801.77 & 33.46 & 0.37 & 2.26 & 0.79 & 2.24 & 0.473 & 2.67E-02 \\
\hline 39275 & 1445.62 & 37.36 & 0.47 & 2.59 & 0.79 & 2.96 & 0.521 & 4.87E-03 \\
\hline 56493 & 1716.66 & 20.18 & 0.47 & 2.56 & 0.79 & 2.74 & 0.556 & $2.11 \mathrm{E}-02$ \\
\hline 41972 & 1478.61 & 39.3 & 0.53 & 2.75 & 0.84 & 2.95 & 0.588 & 3.16E-03 \\
\hline 24168 & 1195.48 & 37.51 & 0.58 & 2.8 & 0.84 & 3.26 & 0.593 & 3.12E-03 \\
\hline 107858 & 2751.34 & 29.23 & 0.63 & 2.36 & 0.89 & 2.69 & 0.621 & 3.00E-03 \\
\hline 23356 & 1179.52 & 37.49 & 0.58 & 2.63 & 0.84 & 2.9 & 0.626 & $2.67 \mathrm{E}-02$ \\
\hline 97599 & 2547.99 & 21.44 & 0.58 & 2.59 & 0.89 & 2.66 & 0.635 & $3.15 \mathrm{E}-02$ \\
\hline 8695 & 949.22 & 34.33 & 0.53 & 2.46 & 0.68 & 3.01 & 0.637 & $2.78 \mathrm{E}-02$ \\
\hline
\end{tabular}




\begin{tabular}{|c|c|c|c|c|c|c|c|c|}
\hline \multicolumn{3}{|c|}{ Peptide } & \multicolumn{2}{|c|}{ Cases } & \multicolumn{2}{|c|}{ Controls } & \multirow[b]{2}{*}{$\mathrm{R}$} & \multirow[b]{2}{*}{$\begin{array}{c}P \text {-value } \\
\text { (Unadjusted) }\end{array}$} \\
\hline ID & $\begin{array}{l}\text { Mass } \\
(\mathrm{Da})\end{array}$ & $\begin{array}{l}\text { CE Time } \\
(\min )\end{array}$ & $\%$ & MA & $\%$ & MA & & \\
\hline 23697 & 1186.53 & 22.39 & 0.68 & 2.8 & 1 & 2.88 & 0.661 & $2.08 \mathrm{E}-02$ \\
\hline 36566 & 1401.38 & 36.56 & 0.58 & 2.77 & 0.74 & 3.27 & 0.664 & 8.74E-03 \\
\hline 153832 & 4196.75 & 20.84 & 0.68 & 2.41 & 0.95 & 2.59 & 0.666 & 4.93E-03 \\
\hline 26670 & 1235.56 & 26.65 & 0.63 & 3.02 & 0.84 & 3.3 & 0.686 & 1.08E-02 \\
\hline 58050 & 1749.81 & 30.61 & 0.63 & 2.57 & 0.84 & 2.79 & 0.691 & 3.04E-02 \\
\hline 28005 & 1255.48 & 35.77 & 0.68 & 3.08 & 0.84 & 3.4 & 0.733 & 3.19E-02 \\
\hline 159396 & 4409.89 & 20 & 0.74 & 2.72 & 0.84 & 3.23 & 0.742 & 2.68E-02 \\
\hline 69979 & 1996.79 & 20.98 & 0.79 & 2.86 & 0.95 & 3.17 & 0.750 & 8.53E-03 \\
\hline 40737 & 1462.62 & 39.42 & 0.84 & 3.33 & 1 & 3.68 & 0.760 & 2.62E-04 \\
\hline 65368 & 1901.82 & 43.83 & 0.79 & 3.17 & 0.89 & 3.61 & 0.779 & $1.52 E-02$ \\
\hline 128086 & 3286.55 & 30.92 & 0.79 & 3.13 & 0.89 & 3.51 & 0.792 & 6.91E-04 \\
\hline 73434 & 2067.82 & 20.62 & 0.84 & 3.1 & 1 & 3.28 & 0.794 & 1.42E-02 \\
\hline 148086 & 3986.65 & 20.6 & 0.84 & 3.53 & 0.95 & 3.82 & 0.817 & 2.75E-03 \\
\hline 108574 & 2764.21 & 42.63 & 0.79 & 3.56 & 0.89 & 3.85 & 0.821 & $2.43 E-02$ \\
\hline 90344 & 2377.1 & 20.8 & 0.89 & 3.12 & 0.95 & 3.46 & 0.845 & 1.95E-02 \\
\hline 36759 & 1405.61 & 39.04 & 0.89 & 2.94 & 0.95 & 3.18 & 0.866 & 1.02E-02 \\
\hline 147541 & 3968.6 & 21.09 & 0.89 & 3.14 & 0.89 & 3.57 & 0.880 & 1.77E-03 \\
\hline 28561 & 1265.59 & 27.09 & 0.89 & 3.36 & 0.89 & 3.79 & 0.887 & 1.10E-02 \\
\hline 107460 & 2742.25 & 28.98 & 0.95 & 2.91 & 1 & 3.11 & 0.889 & 1.19E-02 \\
\hline 32171 & 1321.59 & 28.37 & 0.95 & 4.07 & 1 & 4.27 & 0.906 & 1.82E-02 \\
\hline 39322 & 1446.64 & 39.43 & 1 & 3.2 & 1 & 3.49 & 0.917 & 3.19E-02 \\
\hline 35339 & 1378.61 & 28.82 & 1 & 3.36 & 1 & 3.53 & 0.952 & $1.54 \mathrm{E}-02$ \\
\hline 81196 & 2210.95 & 33.61 & 1 & 3.72 & 1 & 3.59 & 1.036 & 2.15E-02 \\
\hline 41601 & 1469.67 & 23.69 & 1 & 3.72 & 1 & 3.56 & 1.045 & 2.33E-02 \\
\hline 62866 & 1854.81 & 40.92 & 1 & 3.89 & 1 & 3.71 & 1.048 & 1.98E-02 \\
\hline 99021 & 2570.19 & 42.56 & 1 & 3.88 & 1 & 3.7 & 1.049 & 1.19E-02 \\
\hline 79136 & 2175 & 33.28 & 1 & 3.74 & 1 & 3.49 & 1.072 & 1.09E-02 \\
\hline 50840 & 1623.73 & 24.12 & 0.95 & 4.17 & 0.95 & 3.86 & 1.080 & 9.77E-03 \\
\hline 72533 & 2046.92 & 32.58 & 0.95 & 3.49 & 0.95 & 3.21 & 1.087 & 1.06E-02 \\
\hline 57537 & 1737.78 & 23.73 & 1 & 4.02 & 0.95 & 3.82 & 1.108 & $2.15 \mathrm{E}-02$ \\
\hline 50212 & 1613.82 & 23.99 & 0.89 & 2.7 & 0.89 & 2.43 & 1.111 & 3.30E-02 \\
\hline 60149 & 1794.8 & 23.92 & 1 & 3.72 & 0.95 & 3.47 & 1.128 & $6.20 \mathrm{E}-03$ \\
\hline 103198 & 2654.19 & 23.92 & 0.89 & 2.94 & 0.89 & 2.47 & 1.190 & $5.52 E-03$ \\
\hline 104786 & 2679.2 & 23.53 & 1 & 3.58 & 0.89 & 3.34 & 1.204 & 7.89E-03 \\
\hline
\end{tabular}




\begin{tabular}{|c|c|c|c|c|c|c|c|c|}
\hline \multicolumn{3}{|c|}{ Peptide } & \multicolumn{2}{c|}{ Cases } & \multicolumn{2}{c|}{ Controls } & \\
\hline ID & $\begin{array}{c}\text { Mass } \\
(\mathrm{Da})\end{array}$ & $\begin{array}{c}\text { CE Time } \\
(\mathrm{min})\end{array}$ & $\%$ & MA & $\%$ & MA & $R$ & $\begin{array}{c}P \text {-value } \\
\text { (Unadjusted) }\end{array}$ \\
\hline 33135 & 1338.6 & 23.99 & 1 & 2.86 & 0.89 & 2.65 & 1.213 & $1.20 \mathrm{E}-02$ \\
\hline 73291 & 2064.92 & 24.46 & 0.84 & 2.75 & 0.79 & 2.37 & 1.234 & $3.25 \mathrm{E}-02$ \\
\hline 45021 & 1532.62 & 26.35 & 1 & 2.82 & 0.89 & 2.55 & 1.243 & $1.67 \mathrm{E}-02$ \\
\hline 99475 & 2577.25 & 24.67 & 0.95 & 2.78 & 0.89 & 2.38 & 1.247 & $6.05 \mathrm{E}-03$ \\
\hline 40294 & 1452.66 & 23.61 & 1 & 2.85 & 0.84 & 2.62 & 1.295 & $2.17 \mathrm{E}-03$ \\
\hline 35424 & 1380.64 & 23.83 & 0.95 & 2.79 & 0.79 & 2.56 & 1.311 & $7.17 \mathrm{E}-03$ \\
\hline 131294 & 3375.57 & 31.92 & 1 & 2.87 & 0.79 & 2.71 & 1.341 & $1.80 \mathrm{E}-02$ \\
\hline 111564 & 2841.26 & 24.54 & 0.89 & 3.21 & 0.79 & 2.67 & 1.354 & $4.98 \mathrm{E}-03$ \\
\hline 104195 & 2663.2 & 23.51 & 0.89 & 2.61 & 0.74 & 2.29 & 1.371 & $2.07 \mathrm{E}-02$ \\
\hline 28747 & 1268.57 & 27.25 & 1 & 3.44 & 0.74 & 3.32 & 1.400 & $1.01 \mathrm{E}-02$ \\
\hline 44802 & 1526.69 & 23.92 & 0.79 & 2.51 & 0.63 & 2.1 & 1.499 & $1.10 \mathrm{E}-02$ \\
\hline 113452 & 2889.35 & 24.08 & 0.89 & 2.47 & 0.58 & 2.29 & 1.655 & $7.34 \mathrm{E}-03$ \\
\hline 69681 & 1989.88 & 32.44 & 0.84 & 2.43 & 0.42 & 2.51 & 1.936 & $2.03 \mathrm{E}-02$ \\
\hline 55516 & 1696.72 & 23.95 & 0.79 & 2.54 & 0.42 & 2.39 & 1.999 & $1.59 \mathrm{E}-02$ \\
\hline 80360 & 2196.02 & 33.16 & 0.68 & 2.74 & 0.26 & 2.73 & 2.625 & $1.15 \mathrm{E}-02$ \\
\hline 82784 & 2236.98 & 27.14 & 0.63 & 2.28 & 0.21 & 2.31 & 2.961 & $1.29 \mathrm{E}-02$ \\
\hline 56806 & 1723.52 & 37.74 & 0.53 & 2.31 & 0.11 & 2.52 & 4.417 & $1.03 \mathrm{E}-02$ \\
\hline 129182 & 3320.51 & 24.25 & 0.47 & 2.07 & 0.05 & 2.1 & 9.266 & $4.71 \mathrm{E}-03$ \\
\hline
\end{tabular}

ID, peptide identifier (SQL number); \%, percentage of samples, in which the peptide could be detected; MA, mean signal amplitude of the peptides. $R$ was calculated as $\Sigma$ (In signal amplitude $x$ frequency/number of participants) in cases divided by $\sum$ (In signal amplitude $x$ frequency/number of participants) in controls. The peptides were ordered by ascending $R$. Reproduced from reference 7. 
Table S2. List of Peptides Included in HF1 with Available Information on Amino-Acid Sequence

\begin{tabular}{|c|c|c|c|c|c|c|c|}
\hline \multirow{2}{*}{ ID } & \multirow{2}{*}{ Sequence of Peptide } & \multirow{2}{*}{ Protein Name } & \multicolumn{2}{|c|}{ Cases } & \multicolumn{2}{|c|}{ Controls } & \multirow[b]{2}{*}{$\mathrm{R}$} \\
\hline & & & $\%$ & MA & $\%$ & MA & \\
\hline 8725 & GDAGSKGpmV & Collagen alpha-1(V) & 0.05 & 1.94 & 0.63 & 2.28 & 0.067 \\
\hline 123106 & RDVEEEEEEEGLEEDAELLTELQEVLG & Coiled-coil and $\mathrm{C} 2$ domain-containing protein $1 \mathrm{~B}$ & 0.05 & 1.98 & 0.47 & 2.63 & 0.080 \\
\hline 1577 & KGDTGPpGP & Collagen alpha-1(III) & 0.05 & 1.65 & 0.47 & 1.85 & 0.095 \\
\hline 103493 & DEAGSEADHEGTHSTKRGHAKSRPV & Fibrinogen alpha & 0.05 & 3.36 & 0.47 & 3.29 & 0.109 \\
\hline 44146 & DDFDAHKALEDDE & Isoform 1 of Histone-lysine N-methyltransferase MLL2 & 0.11 & 1.91 & 0.58 & 2.49 & 0.146 \\
\hline 4845 & GGSGAmGSmD & $\begin{array}{l}\text { Immunoglobulin-like and fibronectin type III domain- } \\
\text { containing protein } 1\end{array}$ & 0.16 & 1.55 & 0.63 & 2.44 & 0.161 \\
\hline 37610 & GPpGpPGSpGEQGPSG & Collagen alpha- $1(\mathrm{I})$ & 0.11 & 1.73 & 0.53 & 1.87 & 0.192 \\
\hline 83441 & GAVGEKGEPGEAGEpGLpGEGGPpG & Collagen alpha-1(V) & 0.11 & 3.45 & 0.53 & 3.56 & 0.201 \\
\hline 74703 & KSSSHQDSSRmSSVGDYNT & Bone morphogenetic protein 5 & 0.11 & 2.64 & 0.53 & 2.7 & 0.203 \\
\hline 101157 & GPpGADGQpGAKGEpGDAGAKGDAGpPGPA & Collagen alpha- $1(\mathrm{I})$ & 0.11 & 1.97 & 0.53 & 1.98 & 0.207 \\
\hline 103022 & FNINNLDNNWLKMHFWFYYA & Dermatan-sulfate epimerase-like protein & 0.16 & 2.52 & 0.68 & 2.56 & 0.232 \\
\hline 46091 & KGETGDVGQMGppGPP & Collagen alpha-1(V) & 0.16 & 2.08 & 0.53 & 2.24 & 0.280 \\
\hline 32022 & TYFPHFDLSHG & Hemoglobin subunit alpha & 0.21 & 1.99 & 0.58 & 2.21 & 0.326 \\
\hline 82708 & GRTGDAGPVGPPGPpGppGpPGPPS & Collagen alpha-1(I) & 0.32 & 2.57 & 0.84 & 2.68 & 0.365 \\
\hline 98089 & DEAGSEADHEGTHSTKRGHAKSRP & Fibrinogen alpha & 0.32 & 2.97 & 0.84 & 3 & 0.377 \\
\hline 61984 & DQDKHDDSTDDSDTDK & WW domain-binding protein 11 & 0.53 & 2.64 & 1 & 3.12 & 0.448 \\
\hline 46369 & GPpGEKGGQGPPGpQGp & Collagen alpha-1(V) & 0.32 & 2.78 & 0.68 & 2.84 & 0.461 \\
\hline 143947 & $\begin{array}{l}\text { DQGPVGRTGEVGAVGPpGFAGEKGPSGEA } \\
\text { GTAGPpGTpGPQG }\end{array}$ & Collagen alpha-2(I) & 0.37 & 2.26 & 0.79 & 2.24 & 0.472 \\
\hline 39275 & DGVGQpGLPGpPGPpG & Collagen alpha- $1(\mathrm{XVIII})$ & 0.47 & 2.59 & 0.79 & 2.96 & 0.520 \\
\hline 56493 & KGDEGEAGDPGDDNNDI & Collagen alpha-1(VI) & 0.47 & 2.56 & 0.79 & 2.74 & 0.556 \\
\hline 41972 & EQGLpGAAGQDGPpGP & Isoform D preproprotein of collagen alpha-1 (XI) & 0.53 & 2.75 & 0.84 & 2.95 & 0.588 \\
\hline 24168 & GPpGPPGPSSNQG & Collagen alpha-6(IV) & 0.58 & 2.8 & 0.84 & 3.26 & 0.593 \\
\hline 107858 & VSESSIHIIGVSLGAHVGGmVGQLFGGQ & Isoform 2 of phospholipase A1 member A & 0.63 & 2.36 & 0.89 & 2.69 & 0.621 \\
\hline
\end{tabular}


Page 11 of 17

\begin{tabular}{|c|c|c|c|c|c|c|c|}
\hline \multirow{2}{*}{ ID } & \multirow{2}{*}{ Sequence of Peptide } & \multirow{2}{*}{ Protein Name } & \multicolumn{2}{|c|}{ Cases } & \multicolumn{2}{|c|}{ Controls } & \multirow[b]{2}{*}{$\mathrm{R}$} \\
\hline & & & $\%$ & MA & $\%$ & MA & \\
\hline 23356 & GPpGPpGPSSNQG & Collagen alpha-6(IV) & 0.58 & 2.63 & 0.84 & 2.9 & 0.626 \\
\hline 97599 & LGSHSQDEEDEDTEYFDAMEDS & $101 \mathrm{kDa}$ protein & 0.58 & 2.59 & 0.89 & 2.66 & 0.634 \\
\hline 23697 & DDGEAGKpGRpG & Collagen alpha-1(I) & 0.68 & 2.8 & 1 & 2.88 & 0.661 \\
\hline 36566 & EEEDSSDSSSDSE & Isoform 1 of AP-3 complex subunit beta- 1 & 0.58 & 2.77 & 0.74 & 3.27 & 0.664 \\
\hline 26670 & GQDGRpGPpGPpG & Collagen alpha-1(I) & 0.63 & 3.02 & 0.84 & 3.3 & 0.686 \\
\hline 58050 & GPpGEAGKpGEQGVPGDLG & Collagen alpha-1(I) & 0.63 & 2.57 & 0.84 & 2.79 & 0.691 \\
\hline 28005 & TYFPHFDLSHG & Hemoglobin subunit alpha & 0.68 & 3.08 & 0.84 & 3.4 & 0.733 \\
\hline 69979 & KGSpGSDGpKGEKGDPGpEGP & Isoform $2 \mathrm{C}_{2} \mathrm{~A}^{\prime}$ of collagen alpha-2(VI) chain & 0.79 & 2.86 & 0.95 & 3.17 & 0.750 \\
\hline 40737 & GPpGPAGNpGpSpNSP & Isoform 1 of collagen alpha- $1(X X V I)$ & 0.84 & 3.33 & 1 & 3.68 & 0.760 \\
\hline 65368 & WIDAPDDVFYMATEET & Metastasis-associated protein MTA1 $79 \mathrm{kDa}$ protein & 0.79 & 3.17 & 0.89 & 3.61 & 0.779 \\
\hline 73434 & ADGSDLDAVSHGSmDSGHGTH & C-myc promoter-binding protein isoform 1 & 0.84 & 3.1 & 1 & 3.28 & 0.794 \\
\hline 108574 & DmGPpGPQGPpGKDGPPGVKGENGHPGSP & Isoform 2 of collagen alpha-1 (XIII) & 0.79 & 3.56 & 0.89 & 3.85 & 0.821 \\
\hline 90344 & GKNGDDGEAGKpGRpGERGPpGPQ & Collagen alpha- $1(\mathrm{I})$ & 0.89 & 3.12 & 0.95 & 3.46 & 0.845 \\
\hline 36759 & PpGPpGFPGDpGPpG & Collagen alpha-3(V) & 0.89 & 2.94 & 0.95 & 3.18 & 0.866 \\
\hline 28561 & SpGPDGKTGPpGPA & Collagen alpha-1(I) & 0.89 & 3.36 & 0.89 & 3.79 & 0.886 \\
\hline 107460 & KNGETGPQGPPGPTGPGGDKGDTGPpGpQG & Collagen alpha-1(III) & 0.95 & 2.91 & 1 & 3.11 & 0.889 \\
\hline 32171 & ApGDRGEpGPpGPA & Collagen alpha-1(I) & 0.95 & 4.07 & 1 & 4.27 & 0.905 \\
\hline 39322 & GPpGPpGFPGDPGPpG & Collagen alpha-3(V) & 1 & 3.2 & 1 & 3.49 & 0.917 \\
\hline 35339 & ApGEDGRpGPpGPQ & Collagen alpha-1(II) & 1 & 3.36 & 1 & 3.53 & 0.952 \\
\hline 81196 & NGApGNDGAKGDAGApGApGSQGApG & Collagen alpha-1(I) & 1 & 3.72 & 1 & 3.59 & 1.036 \\
\hline 41601 & DGQPGAKGEpGDAGAK & Collagen alpha- $1(\mathrm{I})$ & 1 & 3.72 & 1 & 3.56 & 1.045 \\
\hline 62866 & SGpQGppGSEGFTGPPGPQG & Collagen alpha-2(IV) & 1 & 3.89 & 1 & 3.71 & 1.048 \\
\hline 99021 & QQEQLQQQQFQQQQEQLQQQ & Zinc finger protein 853 & 1 & 3.88 & 1 & 3.7 & 1.049 \\
\hline 79136 & AGPpGEAGKpGEQGVpGDLGApGP & Collagen alpha-1(I) & 1 & 3.74 & 1 & 3.49 & 1.072 \\
\hline 50840 & DGApGKNGERGGpGGpGP & Collagen alpha-1(III) & 0.95 & 4.17 & 0.95 & 3.86 & 1.080 \\
\hline 72533 & PpGEAGKpGEQGVpGDLGApGP & Collagen alpha-1(I) & 0.95 & 3.49 & 0.95 & 3.21 & 1.087 \\
\hline
\end{tabular}


Page 12 of 17

\begin{tabular}{|c|c|c|c|c|c|c|c|}
\hline \multirow{2}{*}{ ID } & \multirow{2}{*}{ Sequence of Peptide } & \multirow{2}{*}{ Protein Name } & \multicolumn{2}{|c|}{ Cases } & \multicolumn{2}{|c|}{ Controls } & \multirow[b]{2}{*}{$\mathrm{R}$} \\
\hline & & & $\%$ & MA & $\%$ & MA & \\
\hline 57537 & NDGApGKNGERGGpGGpGP & Collagen alpha-1(III) & 1 & 4.02 & 0.95 & 3.82 & 1.108 \\
\hline 50212 & VGGGEQPPPAPAPRRE & Xylosyltransferase 1 & 0.89 & 2.7 & 0.89 & 2.43 & 1.111 \\
\hline 60149 & GNDGApGKNGERGGpGGpGP & Collagen alpha-1(III) & 1 & 3.72 & 0.95 & 3.47 & 1.128 \\
\hline 103198 & ERGEAGIpGVpGAKGEDGKDGSpGEpGA & Collagen alpha-1(III) & 0.89 & 2.94 & 0.89 & 2.47 & 1.190 \\
\hline 104786 & NRGERGSEGSPGHpGQpGppGpPGAPGP & Collagen alpha-1(III) & 1 & 3.58 & 0.89 & 3.34 & 1.204 \\
\hline 33135 & GAPGPRGRDGEpGT & Isoform 1 of collagen alpha-1(II) & 1 & 2.86 & 0.89 & 2.65 & 1.213 \\
\hline 73291 & DDKDEEDSPRPRSPPGGPD & Zinc finger and BTB domain-containing protein 46 & 0.84 & 2.75 & 0.79 & 2.37 & 1.234 \\
\hline 45021 & RDGEPGTPGNpGPpGP & Isoform 1 of collagen alpha-1(II) & 1 & 2.82 & 0.89 & 2.55 & 1.243 \\
\hline 99475 & DDILASPPRLPEPQPYPGAPHHSS & Collagen alpha-1 (XVIII) & 0.95 & 2.78 & 0.89 & 2.38 & 1.246 \\
\hline 40294 & DEPPQSPWDRVK & Apolipoprotein A-I & 1 & 2.85 & 0.84 & 2.62 & 1.295 \\
\hline 35424 & AMFGPKGFGRGGAE & Cysteine-rich protein 1 & 0.95 & 2.79 & 0.79 & 2.56 & 1.311 \\
\hline 131294 & PGEDGEpGRNGNPGEVGFAGSpGARGFPGAPGLPGL & Collagen alpha-2(V) & 1 & 2.87 & 0.79 & 2.71 & 1.341 \\
\hline 111564 & ERGEAGIpGVpGAkGEDGKDGSpGEpGANG & Collagen alpha-1(III) & 0.89 & 3.21 & 0.79 & 2.67 & 1.354 \\
\hline 104195 & NRGERGSEGSPGHPGQPGPpGppGApGP & Collagen alpha-1(III) & 0.89 & 2.61 & 0.74 & 2.29 & 1.371 \\
\hline 28747 & SpGERGETGPpGP & Collagen alpha-1(III) & 1 & 3.44 & 0.74 & 3.32 & 1.400 \\
\hline 44802 & GGAGEpGKNGAKGEpGp & Isoform 1 of collagen alpha-1(III) & 0.79 & 2.51 & 0.63 & 2.1 & 1.499 \\
\hline 113452 & NGEAGSAGPpGppGLRGSpGSRGLPGADGRAG & Collagen alpha-2(I) & 0.89 & 2.47 & 0.58 & 2.29 & 1.655 \\
\hline 69681 & SNGNpGPpGPSGSpGKDGPpGP & Collagen alpha-1(III) & 0.84 & 2.43 & 0.42 & 2.51 & 1.936 \\
\hline 55516 & RGSGGGGGGGGQGSTNYGKS & Isoform 3 of heterogeneous nuclear ribonucleoprotein $A / B$ & 0.79 & 2.54 & 0.42 & 2.39 & 1.999 \\
\hline 80360 & ISVPGPMGPSGPRGLpGPpGApGP & Collagen alpha-1(I) & 0.68 & 2.74 & 0.26 & 2.73 & 2.625 \\
\hline 82784 & ADGQpGAkGEpGDAGAKGDAGPpGP & Collagen alpha-1(III) & 0.63 & 2.28 & 0.21 & 2.31 & 2.961 \\
\hline
\end{tabular}

ID, peptide identifier (SQL number); \%, percentage of samples, in which the peptide could be detected; MA, mean signal amplitude of the peptides. R was calculated as $\Sigma$ (In signal amplitude $x$ frequency/number of participants) in controls divided by $\Sigma$ (In signal amplitude $\mathrm{x}$ frequency/number of participants) in cases. The peptides were ordered by ascending R.

Reproduced from reference 7. 
Table S3. Fatal and Nonfatal Cardiovascular Events

\begin{tabular}{|c|c|c|}
\hline Endpoint & Type & Number of events \\
\hline \multirow[t]{2}{*}{ Stroke } & Fatal & 3 \\
\hline & Nonfatal & 3 \\
\hline Transient ischaemic attack & Nonfatal & 5 \\
\hline \multirow[t]{2}{*}{ Myocardial infarction } & Fatal & 2 \\
\hline & Nonfatal & 3 \\
\hline Acute coronary syndrome & Nonfatal & 1 \\
\hline Angina pectoris & Nonfatal & 1 \\
\hline Ischaemic cardiomyopathy & Nonfatal & 17 \\
\hline Coronary revascularisation & Nonfatal & 16 \\
\hline \multirow[t]{2}{*}{ Congestive heart failure } & Fatal & 5 \\
\hline & Nonfatal & 16 \\
\hline Atrial fibrillation/arrhythmia & Nonfatal & 6 \\
\hline Atrioventricular block & Nonfatal & 3 \\
\hline \multirow[t]{2}{*}{ Aortic aneurysm } & Fatal & 1 \\
\hline & Nonfatal & 2 \\
\hline Pulmonary heart disease & Nonfatal & 1 \\
\hline Arterial embolism & Nonfatal & 1 \\
\hline Peripheral arterial diseases & Nonfatal & 9 \\
\hline Total number & & 95 \\
\hline
\end{tabular}

Follow-up of the 791 participants spanned a median of 6.1 years (5th to 95th percentile interval, 3.7-7.4). A participant can experience multiple nonfatal events, so that nonfatal events do not add up. In the outcome analyses, only the first event within each category was considered. 
Table S4. Crude Event Rates by Thirds of the HF1 Distribution

\begin{tabular}{lcccccc}
\hline $\begin{array}{l}\text { Endpoint } \\
\text { (number of events) }\end{array}$ & & $<-1.42(\mathrm{n}=264)$ & & -1.42 to $-0.68(\mathrm{n}=263)$ & $\mathrm{n}$ \\
\cline { 2 - 6 } & $\mathrm{n}$ & Rate $(95 \% \mathrm{Cl})$ & $\mathrm{n}$ & Rate $(95 \% \mathrm{Cl})$ & $\mathrm{n}$ & $\mathrm{Rate}(95 \% \mathrm{Cl})$ \\
\hline Total mortality $(\mathrm{n}=35)$ & 7 & $4.7(4.6,4.8)$ & 9 & $5.9(5.7,6.0)$ & 19 & $12.5(12.4,12.7)$ \\
Cardiovascular events $(\mathrm{n}=63)$ & 8 & $5.4(5.3,5.5)$ & 17 & $11.4(11.2,11.6)$ & 38 & $26.9(26.6,27.2)$ \\
Cardiac events $(\mathrm{n}=45)$ & 4 & $2.7(2.6,2.8)$ & 13 & $8.7(8.5,8.8)$ & 28 & $19.4(19.1,19.6)$ \\
Coronary events $(\mathrm{n}=22)$ & 3 & $2.0(1.9,2.1)$ & 4 & $2.6(2.5,2.7)$ & 15 & $10.2(10.0,10.4)$ \\
\hline
\end{tabular}

Rates (95\% confidence interval) are expressed as number of events per 1000 person-years. 
Table S5. Covariables Associated with Cardiovascular and Cardiac Risk Selected by a Step-Down Procedure

\begin{tabular}{|c|c|c|c|c|}
\hline \multirow{2}{*}{$\begin{array}{l}\text { Selected } \\
\text { covariables }\end{array}$} & \multicolumn{2}{|c|}{ Cardiovascular events } & \multicolumn{2}{|c|}{ Cardiac events } \\
\hline & Hazard ratio $(95 \% \mathrm{Cl})$ & $P$ & Hazard ratio $(95 \% \mathrm{Cl})$ & $P$ \\
\hline Being female $(0,1)$ & $0.57(0.34-0.95)$ & 0.031 & $0.56(0.31-1.03)$ & 0.063 \\
\hline Age $(+15.7$ years $)$ & $3.63(2.55-5.17)$ & $<0.0001$ & $3.21(2.04-5.07)$ & $<0.0001$ \\
\hline Fasting plasma sugar (+0.78 mmol/L) & $1.17(0.99-1.39)$ & 0.063 & $1.30(1.10-1.52)$ & 0.002 \\
\hline Smoking $(0,1)$ & $2.57(1.43-4.60)$ & 0.002 & $1.83(0.89-3.78)$ & 0.10 \\
\hline On treatment with vasodilators $(0,1)$ & $2.04(1.03-4.02)$ & 0.040 & $2.86(1.39-5.91)$ & 0.005 \\
\hline \multicolumn{5}{|c|}{$\begin{array}{l}\text { For age and fasting plasma glucose, hazard ratios express the risk per } 1 \text {-SD increase in the explanatory variable. Models accounted for clustering of } \\
\text { failure times within pedigrees. The baseline characteristics considered as potential covariables were sex, age, body mass index, systolic blood pressure, } \\
\text { fasting plasma glucose, the total-to-HDL cholesterol ratio, } \gamma \text {-glutamyltransferase (as index of alcohol intake), smoking, history of cardiovascular disease, } \\
\text { and treatment with diuretics (thiazides, loop diuretics and aldosterone antagonists), } \beta \text {-blockers, inhibitors of the renin-angiotensin system (angiotensin- } \\
\text { converting-enzyme inhibitors or angiotensin type- } 1 \text { receptor blockers), vasodilators (calcium-channel blockers or } \alpha \text {-blockers), or other antihypertensive } \\
\text { drugs. Covariables to be retained in the analysis were identified by a step-down procedure, removing the least significant covariable at each step until all } \\
P \text {-values of covariables were less than } 0.15 \text {. }\end{array}$} \\
\hline
\end{tabular}




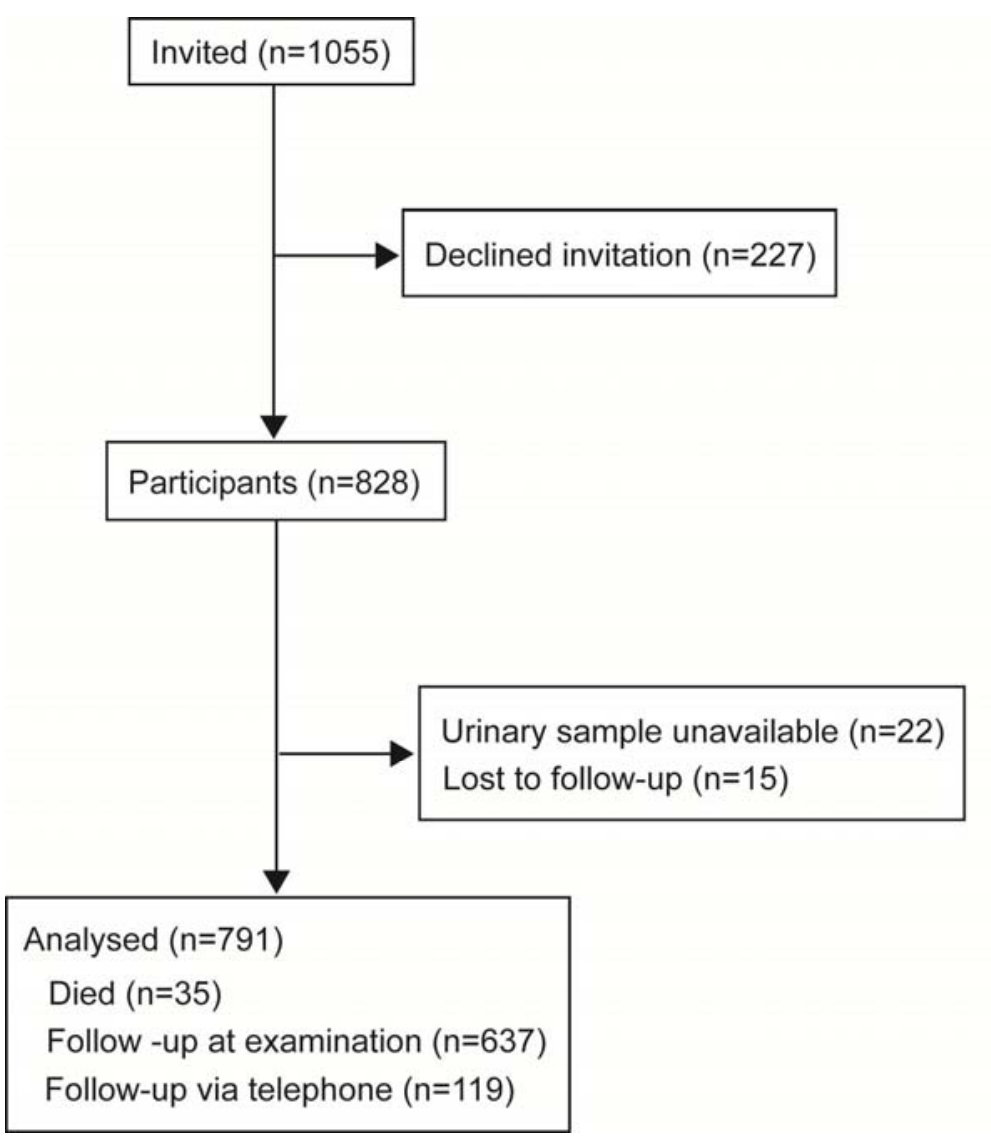

Figure S1. Flow chart. 


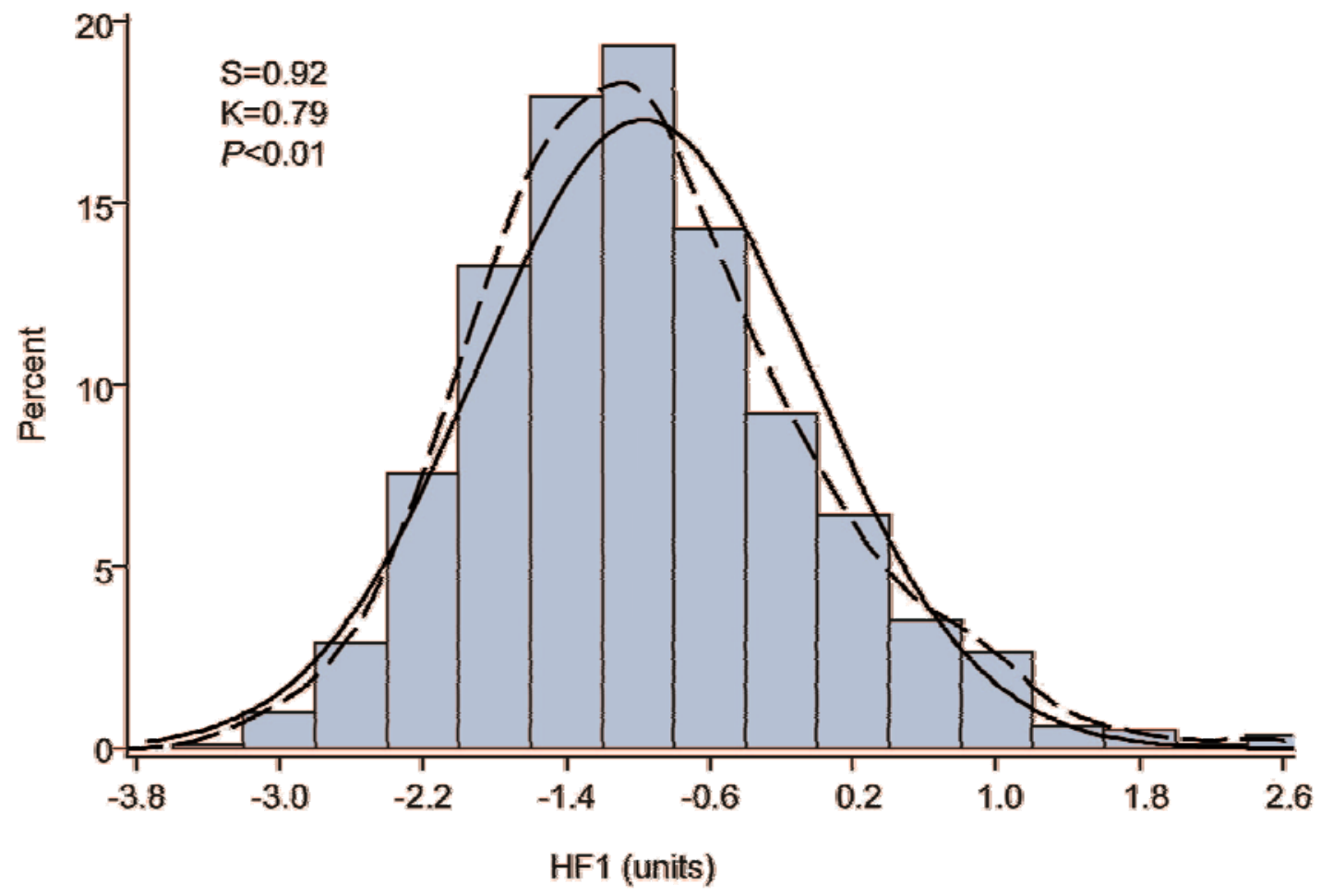

Figure S2. Distribution of the urinary multi-dimensional biomarker HF1 in 791 participants. The curves represent the fitted normal (full line) and kernel (dashed line) density plots. S and $\mathrm{K}$ are the coefficients of skewness and kurtosis, respectively. The P-value is for the Kolmogorov-Smirnov test and indicates departure from normality. 


\section{Urinary Proteome and Systolic Blood Pressure as Predictors of 5-Year Cardiovascular and Cardiac Outcomes in a General Population}

Zhen-Yu Zhang, Lutgarde Thijs, Thibault Petit, Yu-Mei Gu, Lotte Jacobs, Wen-Yi Yang, Yan-Ping Liu, Thomas Koeck, Petra Zürbig, Yu Jin, Peter Verhamme, Jens-Uwe Voigt, Tatiana Kuznetsova, Harald Mischak and Jan A. Staessen

Hypertension. 2015;66:52-60; originally published online May 11, 2015; doi: 10.1161/HYPERTENSIONAHA.115.05296

Hypertension is published by the American Heart Association, 7272 Greenville Avenue, Dallas, TX 75231 Copyright () 2015 American Heart Association, Inc. All rights reserved.

Print ISSN: 0194-911X. Online ISSN: 1524-4563

The online version of this article, along with updated information and services, is located on the World Wide Web at:

http://hyper.ahajournals.org/content/66/1/52

Data Supplement (unedited) at:

http://hyper.ahajournals.org/content/suppl/2015/05/11/HYPERTENSIONAHA.115.05296.DC1.html

\footnotetext{
Permissions: Requests for permissions to reproduce figures, tables, or portions of articles originally published in Hypertension can be obtained via RightsLink, a service of the Copyright Clearance Center, not the Editorial Office. Once the online version of the published article for which permission is being requested is located, click Request Permissions in the middle column of the Web page under Services. Further information about this process is available in the Permissions and Rights Question and Answer document.
}

Reprints: Information about reprints can be found online at: http://www.lww.com/reprints

Subscriptions: Information about subscribing to Hypertension is online at: http://hyper.ahajournals.org//subscriptions/ 